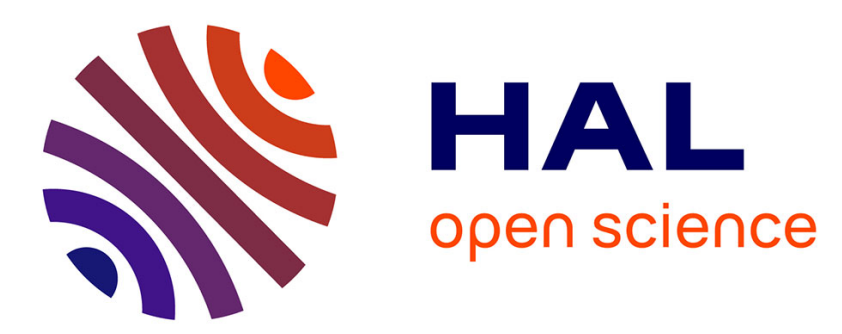

\title{
The equivalent pore aspect ratio as a tool for pore type prediction in carbonate reservoirs
}

François Fournier, Matthieu Pellerin, Quentin Villeneuve, Thomas Teillet, Fei Hong, Emmanuelle Poli, Jean Borgomano, P. Léonide, Alex Hairabian

\section{- To cite this version:}

François Fournier, Matthieu Pellerin, Quentin Villeneuve, Thomas Teillet, Fei Hong, et al.. The equivalent pore aspect ratio as a tool for pore type prediction in carbonate reservoirs. AAPG Bulletin, In press, 10.1306/10181717058 . hal-01739812

\section{HAL Id: hal-01739812 \\ https://hal-amu.archives-ouvertes.fr/hal-01739812}

Submitted on 21 Mar 2018

HAL is a multi-disciplinary open access archive for the deposit and dissemination of scientific research documents, whether they are published or not. The documents may come from teaching and research institutions in France or abroad, or from public or private research centers.
L'archive ouverte pluridisciplinaire HAL, est destinée au dépôt et à la diffusion de documents scientifiques de niveau recherche, publiés ou non, émanant des établissements d'enseignement et de recherche français ou étrangers, des laboratoires publics ou privés. 


\section{AAPG Bulletin \\ The equivalent pore aspect ratio as a tool for pore type prediction in carbonate reservoirs \\ --Manuscript Draft--}

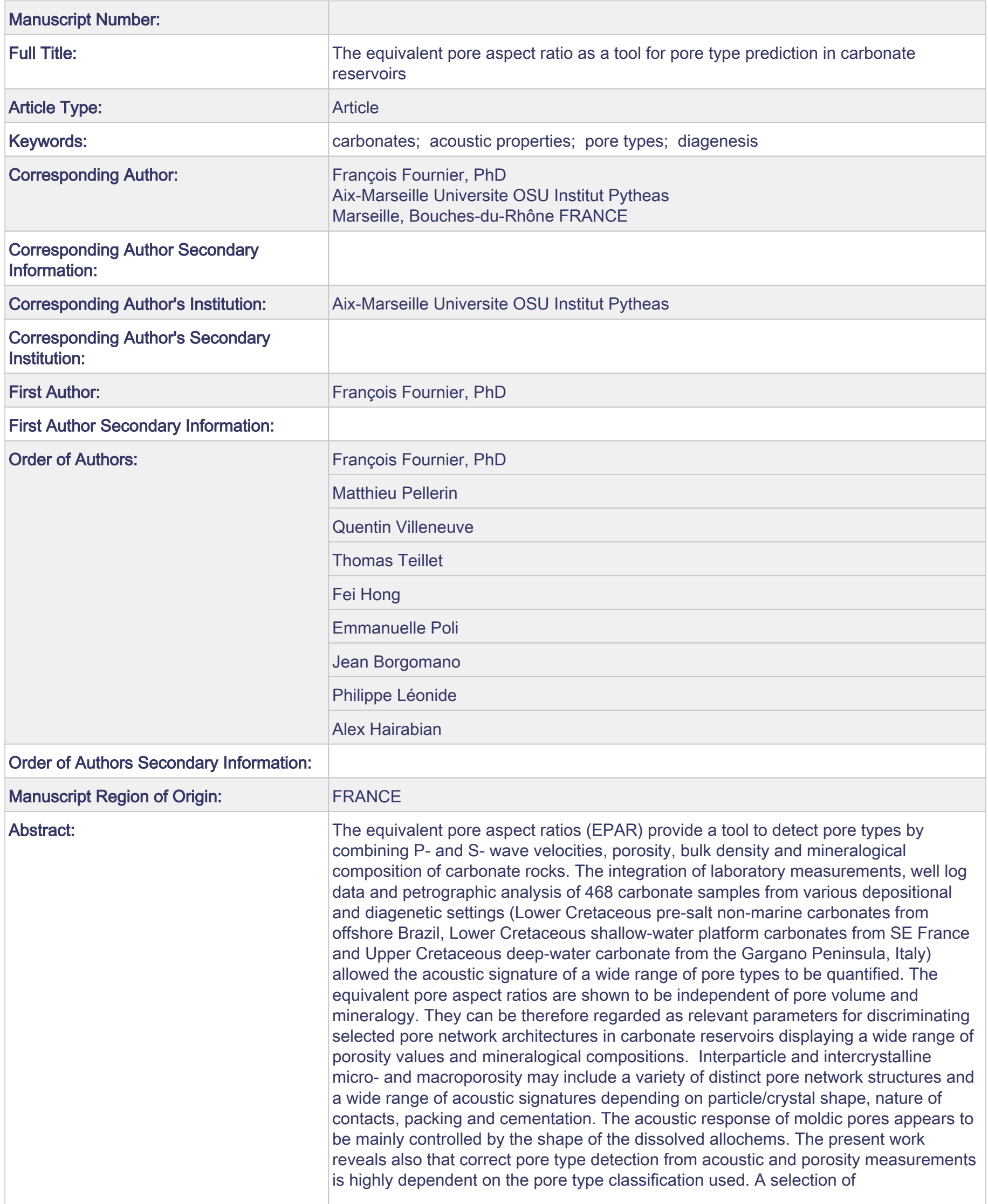




\begin{tabular}{|l|l|}
\hline & $\begin{array}{l}\text { petrographic/diagenetic features to be considered for the construction of a suitable } \\
\text { pore type classification is proposed in order to improve the quantification of the pore } \\
\text { type effect on the acoustic properties of carbonate reservoirs at plug and well-log } \\
\text { scale. }\end{array}$ \\
\hline Suggested Reviewers: & $\begin{array}{l}\text { Gregor Eberli, PhD } \\
\text { Profesor, University of Miami Rosenstiel School of Marine and Atmospheric Science } \\
\text { geberli@rsmas.miami.edu } \\
\text { Gregor Eberli is a major expert in carbonate petroacoustics. He published various } \\
\text { papers aiming at establishing links between carbonate diagenesis, pore network } \\
\text { evolution and acoustic properties. }\end{array}$ \\
\hline Opposed Reviewers: & \begin{tabular}{l} 
Response \\
\hline Additional Information:
\end{tabular} \\
\hline Question & \multicolumn{2}{|l}{} \\
\hline
\end{tabular}




\section{The equivalent pore aspect ratio as a tool for pore type prediction in}

\section{carbonate reservoirs}

François Fournier ${ }^{1}$, Matthieu Pellerin ${ }^{2}$, Quentin Villeneuve ${ }^{1}$, Thomas Teillet ${ }^{1}$, Fei Hong ${ }^{3}$, Emmanuelle Poli ${ }^{3}$, Jean Borgomano ${ }^{1}$, Philippe Léonide ${ }^{1}$ and Alex Hairabian ${ }^{1}$

${ }^{1}$ Aix-Marseille Univ, CNRS, IRD, Coll de France, CEREGE, case 67, 3, Place Victor Hugo, F-13331 Marseille, France

2 TOTAL E\&P AMERICAS, LLC., 1201 Louisiana Street, Suite 1800, Houston, TX, 77002, USA

3 TOTAL E\&P RECHERCHE \& DEVELOPMENT, Avenue Larribau, F-64000 Pau, France

\section{ACKNOWLEDGMENTS}

We gratefully acknowledge TOTAL for the access to the pre-salt data and the permission to publish this work. This paper significantly benefited from stimulating discussions with many TOTAL staffs in research and operational business units. We also thank ENI for having funded the $\mathrm{PhD}$ work of A. Hairabian and for their contribution to the acquisition of the Gargano limestones database.

\section{ABSTRACT}

The equivalent pore aspect ratios (EPAR) provide a tool to detect pore types by combining Pand S- wave velocities, porosity, bulk density and mineralogical composition of carbonate rocks. The integration of laboratory measurements, well log data and petrographic analysis of 
468 carbonate samples from various depositional and diagenetic settings (Lower Cretaceous pre-salt non-marine carbonates from offshore Brazil, Lower Cretaceous shallow-water platform carbonates from SE France and Upper Cretaceous deep-water carbonate from the Gargano Peninsula, Italy) allowed the acoustic signature of a wide range of pore types to be quantified. The equivalent pore aspect ratios are shown to be independent of pore volume and mineralogy. They can be therefore regarded as relevant parameters for discriminating selected pore network architectures in carbonate reservoirs displaying a wide range of porosity values and mineralogical compositions. Interparticle and intercrystalline micro- and macroporosity may include a variety of distinct pore network structures and a wide range of acoustic signatures depending on particle/crystal shape, nature of contacts, packing and cementation. The acoustic response of moldic pores appears to be mainly controlled by the shape of the dissolved allochems. The present work reveals also that correct pore type detection from acoustic and porosity measurements is highly dependent on the pore type classification used. A selection of petrographic/diagenetic features to be considered for the construction of a suitable pore type classification is proposed in order to improve the quantification of the pore type effect on the acoustic properties of carbonate reservoirs at plug and well-log scale.

\section{INTRODUCTION}

The detection of pore network architectures and related diagenetic features from seismic data is a major challenge for hydrocarbon exploration in carbonate setting. The acoustic properties of carbonate reservoirs at core analysis or wireline log sampling resolution are largely controlled by pore space architecture that is structured by depositional processes and by the subsequent diagenetic modification of the sediment (e.g. Anselmetti and Eberli, 2001; Eberli et 
al., 2003; Kenter et al., 2007). In addition, the seismic expression of carbonates is strongly driven by the $3 \mathrm{D}$ distribution of elastic properties at larger scale $(\sim 1-100 \mathrm{~m}[\sim 3-300 \mathrm{ft}])$ that results from the depositional/stratigraphic architecture of the carbonate system and from its diagenetic evolution (Fournier and Borgomano, 2007). Seismic interpretation and seismic inversion methods in highly heterogeneous sedimentary systems such as pre-salt non-marine carbonate systems, shallow marine carbonate platforms and deep marine gravity-driven systems, require a multi-scale approach integrating sedimentologic, diagenetic, rock physics and seismic data. In this context, the quantification of the pore shape effect on the acoustic properties and its isolation from other parameters such as mineralogy, porosity and heterogeneity are essential for extracting depositional and diagenetic patterns from seismic data.

For a given mineral composition, velocities in carbonates display an overall decreasing trend with increasing porosity but exhibit generally a wide scattering of values for a given porosity (Anselmetti et Eberli, 1993; Eberli et al., 2003; Verwer et al., 2008). Such a scattering in velocity values has been interpreted as expressing a pore type effect (Anselmetti and Eberli, 1999). Hence the idea of defining a "deviation log" (Anselmetti and Eberli, 1999) that represents the deviation between a measured velocity and a reference velocity curve that is given by the time average equation (Wyllie et al., 1956). Assuming proper depth shifting of $\operatorname{logs} /$ core and representative mineralogy, the deviation log identifies the gap between theoretical and observed P-wave velocities for selected pore types. Other methods aim at quantifying the relative abundance of selected pore types by means of petro-acoustic models using idealized pore shapes such as spheres or ellipsoids (e.g. Saleh and Castagna, 2005; Xu and Payne, 2009). Such approaches allow the relative abundance of soft, stiff and reference pores to be estimated from porosity and velocity measurements but fail to establish connections with the actual nature of pores as defined by the petrographic study of carbonate rocks. 
One difficulty in the detection and quantification of pore types from acoustic data is often the choice of the relevant pore classification to be used. Indeed, the conventional pore type classes commonly used in carbonate reservoir studies, such as those derived from the Choquette and Pray (1970) classification, are generally poorly discriminated in velocity-porosity plots (Weger et al., 2009). In addition, in carbonate rocks with high contents in dolomite and silica, P- and S-wave velocities are strongly influenced by the mineral composition (Rafavich et al., 1984; Anselmetti and Eberli, 1993; Kenter et al., 1997). In such rocks the pore type signature of acoustic properties is largely overprinted by the mineral composition (Anselmetti et al., 1997). The deconvolution of the mineral and pore network signal is therefore required for the detection of pore types from acoustic properties in such carbonates.

On the basis of the integration of well log data, laboratory measurements and petrographic analysis of thin-sections from three carbonate systems (lacustrine carbonates from the Brazilian Lower Cretaceous pre-salt interval, Lower Cretaceous shallow marine platform carbonates from SE France, and Upper Cretaceous deep-marine redeposited carbonates from Italy) the present study aims at: 1) quantifying the relative influence of mineralogy, porosity and pore geometry on the acoustic properties of carbonate reservoirs in various depositional and diagenetic settings, 2) detecting pore types from porosity and acoustic property measurements by means of a proxy named EPAR (Equivalent Pore Aspect Ratio) and 3) providing rules for the construction of relevant pore type classifications which are suitable for acoustic property characterization and prediction in carbonates. The three studied databases have been selected with a view to cover a wide range of depositional and diagenetic settings and to integrate a large variety of pore network structures.

\section{DATABASE AND METHODS}




\section{The carbonate rock and acoustic database}

The present work is based on the integration of acoustic measurements and petrographic studies from three carbonate reservoirs: 1) coquina and spherulitic carbonates from the Lower Cretaceous pre-salt interval, offshore Brazil (Figure 1), 2) Lower Cretaceous shallow marine rudist-bearing limestones deposited in the so-called Urgonian platform from Provence, SouthEast France (Figure 2A), and 3) Upper Cretaceous deep-water redeposited carbonates from the Gargano Peninsula, Italy (Figure 2B). The pre-salt database includes cores, side-wall plugs, thin-sections and well-logs from two wells located offshore Brazil. Results from the Provence and Gargano case studies are based on the laboratory acoustic database published respectively by Fournier et al. (2014) and Hairabian et al. (2014) and on a revision of the pore typing for the corresponding samples.

The identification of the depositional and diagenetic features and the definition of pore types are based on the macroscopic observation of carbonate rock samples and on the analysis of thinsections under polarized-light microscopy. Additionally, in the case of the pre-salt database, borehole images have been used to detect larger pores $(>5 \mathrm{~mm})$, such as vugs and open fractures, that are not captured by thin-sectioned plugs. The amount and the nature of the studied samples are summarized in Table 1.

For the subsurface pre-salt database, P- and S-wave velocities, bulk density, fluid and mineral composition of the rocks are determined from well logs at depths corresponding to the position of thin-sectioned plugs. The depth of the plugs has been accurately tied with well-log depths by using borehole imaging. Velocities of dry rocks are computed by using the Gassmann (1951) fluid substitution relationship. Mineral bulk and shear moduli were taken as the average of the lower and upper Hashin-Shtrikman bounds (Hashin and Shtrikman, 1963), given the mineral 
composition of the sample. Effective bulk moduli of fluid mixtures are calculated by using a model of patchy distribution of fluids (arithmetic average of fluid moduli). Mineral and fluid physical parameters (bulk and shear moduli, density) are displayed in Table 2.

For the Provence and Gargano databases, porosity values were determined by using helium pycnometry methods whereas ultrasonic P- and S-wave velocities were measured on dry samples using laboratory transducer arrangement, at various confining pressures. The measurement protocol for these samples is detailed in Fournier et al. (2014) for the Urgonian limestones from Provence and in Hairabian et al. (2014) for the Gargano samples. The ultrasonic velocities integrated in the present paper were measured at $40 \mathrm{MPa}$.

\section{The Equivalent Pore Aspect Ratio (EPAR) approach}

The computation of effective property models such as differential effective models (Cleary et al., 1980; Norris, 1985; Zimmerman, 1991) has been commonly used to model the velocityporosity and elastic moduli-velocity relationships, and to relate them to pore structures in various marine and continental carbonate settings (e.g. Fournier and Borgomano, 2009; Xu and Payne, 2009; Zhao et al., 2013). In order to quantify the effect of pore architecture on the acoustic properties, a petroacoustic index, the Equivalent Pore Aspect Ratio (EPAR), is used and discussed in the present study. As defined by Fournier et al. (2011) the equivalent pore aspect ratio of a carbonate rock is defined as the aspect ratio of an oblate spheroid that is acoustically equivalent to the actual pore network. The Equivalent Pore Aspect Ratio (EPAR) is actually a set of two parameters, $\alpha_{K}$ and $\alpha_{\mu}$ that are calculated by matching respectively the dry bulk and shear moduli derived from laboratory measurements or well logs with differential effective medium (DEM) models of a solid phase (mineral) containing dry oblate spheroidal inclusions. The $\alpha_{K}$ and $\alpha_{\mu}$ parameters are equivalent to the K-EPAR and $\mu$-EPAR defined by 
Fournier et al. (2011), and are renamed in the present work to avoid confusion with elastic moduli. The EPAR approach is summarized in Figure 3. As stated by Fournier et al. (2011; 2014), equivalent pore aspect ratios should not be considered as descriptors of the actual pore shape but as petroacoustic parameters allowing the pore type effect on acoustic properties to be quantified.

In the present study, the acoustic response of pore architectures is calibrated by means of a combined analysis of laboratory measurements, well logs and thin-sections from plugs. The uncertainties related to such approach are therefore:

1) The uncertainties related to laboratory-measured or well-log-derived velocities, porosity and mineral composition of rocks;

2) The scales of investigation: 0.01 to $10 \mathrm{~mm}$ for thin section compared to $1-10 \mathrm{~cm}[\sim 0.4-4 \mathrm{in}]$

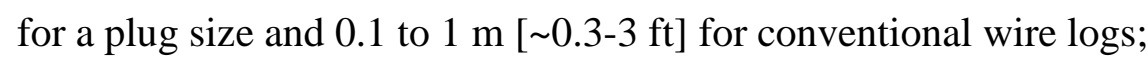

3) The $2 \mathrm{D}$ vs $3 \mathrm{D}$ nature of the investigation: $2 \mathrm{D}$ for thin sections vs $3 \mathrm{D}$ for the laboratory measurement on plugs and for the wire logs.

4) The spatial uncertainty caused by core to log shifting in the case of the subsurface pre-salt database;

In the case of the subsurface pre-salt database, in order to limit the uncertainty related to the scale of investigation, borehole imaging was used to detect larger ( $>5 \mathrm{~mm})$ pores that may not be captured on thin-sections. The uncertainty related to sample positioning was also significantly reduced by correcting the plug depth by using borehole images. In addition, the present approach does not consider possible effects of P- and S-wave anisotropy.

\section{GEOLOGICAL SETTING}




\section{Lower Cretaceous pre-salt lacustrine carbonate reservoirs (offshore Brazil)}

Late Barremian-early Aptian coquinas (Jiquia local stage) and Aptian spherulitic carbonates (Alagoas local stage) are amongst the most prolific and most promising carbonate reservoirs of the pre-salt interval from the Brazilian margin. The Brazilian margin started to form in the Early Cretaceous during the break-up of the Gondwana. The chronostratigraphic framework of the Lower Cretaceous deposits from offshore Brazil is summarized in Figure 1. Thick carbonate deposition occurred in the upper part of the lower syn-rift sequence which corresponds to the Brazilian Jiquia stage and to the international late Barremian-early Aptian interval (Carvalho et al., 2000). It is characterized by a significant development of Molluscan-rich carbonates, the so-called coquina facies (Carvalho et al., 2000; Buckley et al., 2015). The syn-rift pre-Alagoas unconformity is overlain by a carbonate-dominated interval (Alagoas stage) that is characterized by the development of excellent carbonate reservoirs including spherulitic facies, stromatolites and travertine/tufa buildups. The thickness of the Intra-Alagoas carbonate reservoirs can reach 500m in the area (Wright and Barnett, 2015).

Coquina carbonates are widespread pre-salt reservoirs known on the Brazilian margin, from the Santos to the Sergipe-Alagoas basins and on the West African margin from Kwanza to Gabon basins (e.g. Abrahão and Warme, 1990; McArgue, 1990; Thomson et al., 2015). Coquina reservoirs are Mollusk-dominated grainstones to rudstones that are interpreted to have been deposited in non-marine lacustrine environments (Carminatti et al., 2009) even though evidences of marine incursions have been reported onshore within the coquina interval in the Sergipe-Alagoas Basin (Thomson et al., 2015). 
A detailed model for the formation and diagenetic evolution of the non-marine pre-salt spherulitic reservoirs from Brazil has been proposed by Wright and Barnett (2015) and Tosca and Wright (2015). They consider that spherulitic reservoirs are mainly derived from the diagenetic evolution of an initial sediment that is composed of calcitic spherulites that formed coevally with a labile Mg-silicate gel (stevensite) under suitable geochemical conditions in lowenergy, volcanically-influenced lakes. Subsequent changes in lake-water alkalinity promoted the dissolution of stevensite, thus releasing various chemical components that triggered a set of diagenetic transformations in the sediment (dolomitization, silica cementation and replacement, calcite dissolution).

\section{Lower Cretaceous (Barremian-Aptian) shallow-water marine carbonates from Provence}

\section{(SE France)}

In Provence (SE France), the Late Hauterivian to Early Aptian time interval represents the main phase of development of the shallow-water, rudist-bearing, Urgonian platform (Masse, 1993). In terms of age, depositional environments and facies, pore types and reservoir properties, the Urgonian limestones from Provence are considered as relevant outcrop analogues of some Middle East carbonate reservoirs such as those of the Thamama, Kharaib and Shuaiba formations (Borgomano et al., 2013). Urgonian limestones from Provence are dominantly microporous (Fournier et al., 2011), but moldic and intergranular porosity may also represent a significant proportion of the pore volume in such reservoirs (Borgomano et al., 2013; Fournier et al., 2014). A scenario of the pore space evolution in the Urgonian limestones from Provence (SE France) has been proposed by Leonide et al. (2014): 1) microporous limestones have been interpreted to develop by micrite neomorphism processes in a meteoric shallow-burial setting probably during a regional subaerial exposure event (Albian-lower Cenomanian); 2) tight limestones resulted from an early marine and/or meteoric cementation of the intergranular 
macropores and intercrystalline micropores and 3) dissolution of aragonitic shells occurred during early (syn-Urgonian) phases of subaerial exposure whereas a later phase of leaching of possible telogenetic origin led to microporosity enhancement and moldic/vuggy porosity development.

Upper Cretaceous deep-water redeposited carbonates from the Gargano Peninsula (Italy)

The studied limestones crop out exposed close to the town of Monte Sant'Angelo (Figure 2B) in the Gargano Peninsula (SE Italy) which is now part of the relatively undeformed foreland of the Appennine thrust belts (Funiciello et al., 1991). The Gargano Peninsula is, together with the Maiella Mountain, an extensively investigated area where the plaform-to-basin transition of an Upper Cretaceous carbonate system is exposed onland. The stratigraphic framework of the Upper Cretaceous limestones from the Gargano Peninsula is summarized in Figure 2C. The studied carbonate samples exclusively consist of deep-water (several hundred meters of water depth) base-of-slope carbonates, including debris flow, grain flow, turbidite and hemipelagic sediments, deposited at the foot of fault-related escarpments bounding the Apulian Platform (Masse \& Borgomano, 1987; Hairabian et al., 2014).

\section{RESULTS}

\section{Petrographic features and pore typing}


The descriptive pore type classification used in the present paper is summarized in Figure 4.

\section{Lower Cretaceous pre-salt coquinas (offshore Brazil)}

The database consists of 60 samples of bivalve-dominated, grain-supported carbonates with various silica contents (up to $45 \%$ ) and generally low proportions of dolomite, up to $11 \%$ but that are typically lower than 3\% (Figure 5). Two major depositional textures are identified from the studied samples: 1) Molluscan rudstones (Figure 6 D, E) dominated by flat and often whole shells of bivalves and 2) Molluscan grainstones/rudstones dominated by subrounded, abraded pieces of broken bivalve shells (Figure 6 F).

A remarkable diagenetic feature of the present rock database is the near absence of mechanical and chemical compaction features even in poorly cemented coquinas (Figure 6 D). In most of the studied samples, sparry calcite cements occlude partially (Figure 6 D), or entirely (Figure 6 E) the intergranular space of the poorly compacted coquinas. The presence of reworked pebbles of silicified coquinas in some samples (Figure 6 C) suggests evidence for an early phase of silica cementation and silica replacement (microquartz). In addition, thick rims of silica cements and subsequent blocky calcite cements are commonly found to occlude entirely the interskeletal pore space (Figure 6 A, B). Significant dissolution of bivalve shells is observed from a large proportion of the studied samples (Figure 6 A, F). Sparry calcite, microquartz and sometimes dolomite rhombs are present within the resulting moldic pores (Figure $6 \mathbf{C}, \mathbf{F}$ ).

The identification of the textural and diagenetic features allow three dominant pore types to be recognized from the pre-salt coquina database. In Molluscan rudstones with flat and whole shells, when calcite and/or silica cementation are reduced, a primary interskeletal macroporosity (IG1 pore type) may be preserved (Figures 4 and 6 D). In addition, the dissolution of flat and whole bivalve shells in cemented coquinas generates moldic pores (MV1 
pore type) of very elongated shape (Figures 4 and 6 C). In contrast, when subrounded, abraded pieces of bivalves are leached, the resulting moldic pores (MV2 pore type) are nearly-spherical to moderately elongated (Figures 4 and 6 F).

\section{Lower Cretaceous pre-salt lacustrine spherulitic reservoirs (offshore Brazil)}

The studied database consists of 261 samples of grainy carbonates with silica and dolomite content ranging respectively from 0 to $45 \%$ and from 0 to $95 \%$ (Figure 7). Dominant grains are spherulites that consist of mm-scale grains made of dense radiating fibrous calcite (Figure 8 C). They are of various shapes although nearly spherical morphologies are dominant. Grains displaying shrub-like structures are present in very low proportions in a few samples. In a purely descriptive way, two types of spherulitic fabrics are identified on the basis of the density of grains and nature of the grain contacts: 1) densely-packed spherulitic sand with irregular-shaped spherulites with long contacts and 2) loosely-packed spherulitic sand with nearly spherical spherulites, floating or displaying point contacts.

The difference in packing between the two spherulitic fabrics probably results from distinct growth patterns (density of the nucleation loci, spherulite growth velocity) of the spherulites in the initial sediment, but the effect of subsequent mechanical and chemical compaction cannot be ruled out. The importance of compaction processes is difficult to evidence from the petrographic observations of the present database since grain impingement during spherulite growth may mimic sutured or concavo-convex contacts (Figure 8 B, C).

In both fabrics, the intergranular space may display a variety of phases: 1) pores, 2) dolomite rhombs, 3) silica cement and 4) relicts of clay matrix.

Intergranular porosity may be significant (up to 25\%) in both loosely-packed and denselypacked spherulitic sands (Figure 8 A, B). Relicts of clay are present in very small proportions 
$(<1 \%)$ between spherulites in a few samples (Figure 8 A). A remarkable diagenetic feature of the pre-salt spherulitic reservoir is the high proportion of small-sized $(50-100 \mu \mathrm{m})$ dolosparite rhombs (Figure 8 C, D, E) within the inter-spherulite space. Silica cements are also common and display a layered (cm-thick) or patchy (cm-scale) distribution within the spherulitic intervals (Figure 8 E). Finally, dissolution features affecting partially or entirely the calcitic spherulites have been evidenced (Figure 8 F).

As a result of the petrographic analysis, five major pore types have been identified from the Brazilian pre-salt spherulitic reservoir. The intergranular porosity can be subdivided into two distinct pore types depending on grain packing and the nature of the grain contact: 1) the IG2 pore type (Figure 4) is defined as the (secondary) intergranular macroporosity in a denselypacked spherulitic sediment with dominant long contacts, and 2) the IG3 pore type (Figure 4) corresponds to the (secondary) intergranular macroporosity in a loosely-packed spherulitic sediment (=pseudo-fenestral pores). In dolomite-rich samples, the intercrystalline porosity (IC pore type) is dominant (Figures 4 and 8 C). In samples with dominant intercrystalline pore type, total porosity may reach $25 \%$. In a few dolomite-rich samples, together with intercrystalline pores, elongated and corrugated thread-like pores (Figures 4 and 8 D) are present (ICb pore type) within the inter-spherulite space. Finally, the dissolution of calcitic spherulite led to the development of nearly-spherical moldic pores (MV2 pore type: Figure 4).

\section{Lower Cretaceous (Barremian-Aptian) shallow-water marine carbonates from Provence} (SE France)

In the present study, the rock and thin section material from the database published by Fournier et al. (2014) (107 samples) has been reinvestigated in order to revise the pore type classification of the Urgonian limestones from Provence. The analysis of a large collection of SEM pictures 
from the studied samples allowed a revision of the classification of microporosity. The database is made of pure limestones $(\% \mathrm{CaC} 03>98 \%)$ exhibiting various depositional textures (wackestone, packstone, grainstone and rudstones). All samples display various proportions of intercrystalline micropores located within micritic grains and/or matrix and a large proportion of the studied samples are exclusively microporous (Figure 9 C). Micropores are defined as pores with diameter lower than 10 microns (Cantrell and Hagerty, 1999). Three main micrite fabrics have been identified, each with specific types of intercrystalline microporosity. In most of the tight limestones $(<9 \%)$, both matrix and micritized allochems exhibit densely-packed euhedral to subhedral crystals of micrite (=mosaic micrite). The related microporosity (MP1 pore type) consists therefore in very narrow and elongated spaces located between the crystal faces (Figures 4 and 10 E). Microporous limestones (up to 24\%) exhibit two micropore types related to two distinct micrite microfabrics. The micropore type MP2 is actually a micropore type association including intercrystalline microporosity between loosely-packed euhedral/subhedral micrite particles and vuggy microporosity (Figures 4 and 10 A, B, C). In the MP2 pore type association, intercrystalline micropore size ranges from 0.5 to $2 \mu \mathrm{m}$. Vuggy micropores are defined as pore spaces that are located within a micritic medium and whose size is larger than the size of the micrite particles $(1-2 \mu \mathrm{m})$ and lower than $10 \mu \mathrm{m}$. The MP3 pore type association consists of interparticle microporosity between leached, subrounded micrite particles, in association with with vuggy micropores (Figure 4). A common feature of the related micrite microfabric is the coalescence of micrite particles that leads to the formation of larger $(5-10 \mu \mathrm{m})$ aggregates (Figures 4 and 10 D).

As established by Fournier et al. (2014) and confirmed by the present study, macropores in Urgonian limestones from Provence include mainly intergranular and moldic/vuggy pores. The intergranular porosity is preserved preferentially in coarse-grained grainstones and rudstones and consists of a residual space after partial cementation of the sediment (Figure 9 A). The 
resulting pores are relatively equant with isolated voids located in the center of the intergranular pore space (IG4 pore type: Figure 4). Moldic pores derive from various phases of dissolution of aragonitic and calcitic grains (Figure 9 B) and are generally nearly-spherical voids (MV2 pore type: Figure 4). In some cases, the moldic porosity can be enlarged thus leading to the developments of vugs. Calcitic cements may partially occlude the moldic and vuggy porosity.

\section{Upper Cretaceous deep-water redeposited carbonates from the Gargano Peninsula (Italy)}

The present work is based on the reappraisal of a dataset of 56 pure limestone samples (> 95\% $\mathrm{CaCO} 3$ ) that have been collected in deep-water redeposited carbonates (Upper Cretaceous, Gargano peninsula, Italy) and published by Hairabian et al. (2014). Depositional facies include 1) Lithoclastic breccias, 2) Bioclastic packtones to grainstones, 3) Interbedded packstones and wackestones and 4) pelagic lime mud with coccoliths and planktonic foraminifers. The analysis of SEM pictures performed on the studied samples has led to revise the pore type scheme proposed by Hairabian et al. (2014) and to identify 4 types of microporosity. As for the Urgonian limestone database, in low porosity limestones, the dominant microfabric is a densely-packed (= mosaic) micrite associated with the MP1 micropore type (Figures 4 and 10 E). Grain-supported (grainstone/packstone) microporous limestones include intercrystalline and vuggy microporosity in euhedral/subhedral micrite (MP2 micropore type: Figure 4), intercrystalline and vuggy microporosity in subrounded/coalescent micrite (MP3 micropore type: Figures 4 and 10 F, G). In contrast, microporous pelagic lime muds (Figure 11 C) are characterized by interparticle and intra-skeletal microporosity in porous, coccolithophoridderived euhedral micrite (MP4 micropore type: Figures 4 and 10 H). 
An intergranular, pseudo-fenestral macroporosity in loosely-packed carbonate sands (IG3 pore type: Figure 4) has been recognized in various packstones/grainstones which are devoid of cements but display patches of micrite matrix (Figure 11 A). In partially cemented grainstones, the IG4 intergranular porosity has been also identified. Nearly-spherical moldic pores (MV2 pore type: Figure 4), related to the dissolution of calcitic and aragonitic bioclasts are common in the Gargano limestones (Figure 11 B).

\section{Equivalent pore aspect ratios for selected dominant pore types}

The equivalent pore aspect ratios $\alpha_{K}$ and $\alpha_{\mu}$ have been computed for all the studied samples from petroacoustic data and from the mineral composition of rocks. Dominant pore types have been identified for all of the samples from petrographic analysis of rocks and thin sections. Dry bulk and shear moduli, porosity and mineralogy that represent the inputs of the $\alpha_{K}$ and $\alpha_{\mu}$ computations are plotted in Figure 5 for the pre-salt coquinas and in Figure $\mathbf{7}$ for the pre-salt spherulitic facies.

Lower Cretaceous pre-salt lacustrine coquinas (offshore Brazil)

Two domains of dominant pore types can be identified on $\alpha_{K}$-porosity plots (Figure 12A):

- The domain (I) is characterized by low $\alpha_{K}$ values $(<0.13)$ and corresponds to samples with dominant interskeletal macroporosity (IG1 pore type) or with dominant moldic porosity in coquinas with full and flat-shaped bivalve shells (MV1 pore type); 
- The domain (II) is related to samples with $\alpha_{K}$ values higher than 0.13 , that are characterized by dominant moldic pores displaying moderately elongated to nearly spherical shapes (MV2 pore type).

An important result of the $\alpha_{K}$-porosity plots is the lack of correlation, for a given dominant pore type, between $\alpha_{K}$ and porosity.

The $\alpha_{\mu}$-porosity plots (Figure 12B) and $\alpha_{K}-\alpha_{\mu}$ (Figure 12C) plots shows no significant variations in $\alpha_{\mu}$ with porosity and $\alpha_{K}$ changes respectively.

Lower Cretaceous pre-salt spherulitic reservoirs (offshore Brazil)

Three domains of dominant pore types can be identified on $\alpha_{K}$-porosity plots (Figure 13A):

- The domain (I) is characterized by low $\alpha_{K}$ values $(<0.13)$ and corresponds to samples with dominant intracrystalline macroporosity (IC and ICb pore type) or with dominant intergranular porosity in densely-packed grainy sediment (IG2 pore type);

- The domain (II) is related to samples with $\alpha_{K}$ values ranging from 0.13 to 0.18 that are characterized by dominant secondary intergranular (pseudo-fenestral) porosity (IG3 pore type) and rounded moldic pores (MV2 pore type);

-The domain (III) is characterized by the higher $\alpha_{K}$ values $(>0.18)$ at a given porosity and corresponds to samples with dominant moldic porosity (MV2 pore type) only.

Similarly to the coquina case study, the $\alpha_{K}$-porosity plots shows that no correlation exists between $\alpha_{K}$ and porosity, for a given dominant pore type. 
A large overlap of the various pore types is visible on $\alpha_{\mu}$-porosity plots (Figure 13B).

On $\alpha_{K}-\alpha_{\mu}$ plots (Figure 13C), samples exhibits a relatively asymmetric distribution. Most of the samples with dominant intercrystalline macroporosity (IC) or intergranular porosity (IG2 and IG3) have $\alpha_{K}$ values lower than $\alpha_{\mu}$. In contrast, moldic samples have $\alpha_{K}$ higher than $\alpha_{\mu}$.

Lower Cretaceous (Barremian-Aptian) shallow-water marine carbonates from Provence (SE France)

Two main domains can be defined from $\alpha_{K}$-porosity plots (Figure 14A):

-The domain (I) is defined by low values of $\alpha_{K}(<0.22)$ and is related to dominantly microporous samples. Within this domains, two categories of samples are recognized: 1) low porosity limestones (porosity <9\%) with densely-packed (=mosaic) micrite in matrix and/or in micritized allochems (MP1 micropore type) that display low $\alpha_{K}$ values, ranging from 0.09 to 0.13, and 2) microporous limestones (porosity up to 24\%) with intercrystalline and vuggy microporosity in loosely-packed micrite (MP2 and MP3 micropore types) with $\alpha_{K}$ values, ranging from 0.11 to 0.22 .

-The domain (II) is characterized by high $\alpha_{K}$ values $(>0.22)$ and is dominated by samples with nearly-spherical moldic pores (MV2 pore type) or with residual intergranular porosity in partially cemented grainstones (IG4 pore type).

As for the pre-salt coquinas and spherulitic facies case studies, no correlation exists between $\alpha_{K}$ and porosity.

Similar zonations are visible on $\alpha_{\mu}$-porosity plots (Figure 14B) with a domain (I) $\left(\alpha_{\mu}<0.13\right)$ characterized by dominant micropore types MP1 and MP2 and a domain (II) $\left(\left(\alpha_{\mu}>0.13\right)\right.$ 
dominated by rounded moldic pores (MV2), partially cemented intergranular pores (IG4) and MP3 micropores.

As illustrated by the $\alpha_{K}-\alpha_{\mu}$ plots (Figure 14C), the variations of $\alpha_{\mu}$ follow closely those of $\alpha_{K}$, except for the samples with dominant moldic pores and intergranular pores.

\section{Upper Cretaceous redeposited deep-water carbonates from the Gargano Peninsula (Italy)}

The petroacoustic signatures of the identified pore types are identified on the $\alpha_{K}$-porosity and $\alpha_{\mu}$-porosity plots (Figure 14D and 14E). The low porosity $(<6 \%)$ limestones with tight mosaic micrite (MP1 micropore type) are characterized by relatively low $\alpha_{K}$ values $(<0.16)$. Microporous limestones with intercrystalline and vuggy microporosity (MP2 micropore types) display a very narrow range of $\alpha_{K}(0.17-0.22)$. Samples with leached subrounded/coalescent micrite (MP3 pore type) have $\alpha_{K}$ values ranging from 0.16 to 0.25 . One sample with intercrystalline microporosity in coccolithophorid-dominated euhedral micrite (MP4 pore type) displays a $\alpha_{K}$ value of 0.20 . Pseudo-fenestral porosity is characterized by moderately high $\alpha_{K}$ (0.12-0.23), overlapping the range of values for MP2 and MP3 micropore types. Moldic porosity (MV2 pore type) and residual intergranular porosity in partially cemented grainstones (IG4 pore type) are characterized by higher $\alpha_{K}$ with values ranging respectively from 0.19 to 0.39 and from 0.31 to 0.46 . On $\alpha_{\mu}$ - porosity plots, micropores (MP1, MP2, MP3, MP4), and intergranular pores (IG3 and IG4) are characterized by low $\alpha_{\mu}$ values $(<0.20)$ whereas for higher $\alpha_{\mu}$ values (>0.20), only rounded moldic pores have been evidenced (Figure 14E).

Also indicated by the Urgonian limestone database, the variations of $\alpha_{\mu}$ follow closely those of $\alpha_{K}$ (Figure 14F), for microporous (MP1, MP2, MP3, MP4 micropore types) and 
pseudofenestral (IG3), but differ significantly for samples with dominant moldic pores (MV2) and partially cemented intergranular pores (IG4).

\section{DISCUSSION}

\section{Pore network evolution and pore type genesis}

\section{Lower Cretaceous Brazilian pre-salt coquinas}

Pore network evolution in coquinas was controlled by various stages of calcite and silica cementation that occluded partly of entirely the interskeletal pore space. The presence of silicified coquina intraclasts reworked within bivalve grainstones/rudstones (Figure 6 C) suggests that a phase of silica cementation and replacement occurred very early in the diagenetic history. In addition, early phases of silica and/or calcite cementation have probably largely impeded the effect of subsequent mechanical and chemical compaction (Figure 6 D). The role of early phases of silica cementation in the preservation of porosity has been mentioned for the pre-salt coquinas from the Campos Basin (Bertani and Carozzi, 1985; Abrahão and Warme, 1990). The IG1 intergranular pore type (Figure 4) mainly result from a partial occlusion of the interskeletal space by early phases of calcite or silica cementation that probably occurred prior to mechanical compaction. Moldic porosity developed as a result of one or various phases of aragonite and calcite dissolution (Figure 6 E, F). In the Campos Basin, moldic porosity development has been interpreted to occur in meteoric vadose environments during early, repeated phases of subaerial exposure (Bertani and Carozzi, 1985) or during a post-depositional exposure event by fault-controlled meteoric water circulation (Castro, 2006). The distinction between MV1 and MV2 pore types (Figure 4) is mainly related to the shape of the dissolved 
bioclasts and is therefore mainly driven by transport and depositional processes (bioclast fragmentation and abrasion).

\section{Lower Cretaceous Brazilian pre-salt spherulitic facies}

As interpreted by Tosca and Wright (2015) and Wright and Barnett (2015), the mineral composition and the pore space of pre-salt spherulitic reservoirs derive from the diagenetic evolution of an initial sediment composed of a Mg-rich clay (e.g. stevensite) matrix in which calcitic spherulites have grown. Such Mg-silicates are easily destabilized, probably in a very early stage of diagenesis, by $\mathrm{pH}$ and $\mathrm{pCO}_{2}$ fluctuations. As a consequence such $\mathrm{Mg}$-rich clays are very prone to dissolve thus leading to the development of a secondary intergranular porosity between the spherulites. The structure of such a secondary intergranular porosity largely depend on the packing of spherulites. The dissolution of the Mg-clay matrix in a sediment with looselypacked spherulites leaves large pores (Figure 8 A, E) that are commonly larger than the average grain diameter, relatively equant in shape or slightly elongated parallel to depositional laminations. Such pores that have been documented by Terra et al. (2010) are named pseudofenestral pores (IG3 pore type: Figure 4). In contrast, in densely-packed spherulitic sediments, the dissolution of Mg-clay generates relatively narrow pores (Figure 8 B) between spherulites that correspond to the IG2 pore type. Although the density of spherulite packing is probably largely controlled by primary, depositional parameters, the hypothesis of an effect of mechanical and/or chemical compaction cannot be ruled out. In addition, the dissolution of stevensite released various chemical components that generated a set of diagenetic transformations (Tosca and Wright (2015) that strongly controlled the pore space evolution. The release of $\mathrm{Mg}^{2+}$ favored the cannibalization of $\mathrm{Ca}^{2+}$ and induced the formation of dolomite in the inter-spherulite space. Such a process is interpreted to be the origin of intercrystalline porosity (IC pore type) development in spherulitic reservoirs. In dolomite-rich spherulitic 
reservoirs, corrugated, thread-shape pores (ICb pore type) may occur and are interpreted as resulting from a later phase of dissolution of clay laminae. The release of $\mathrm{SiO}_{2}$ due to stevensite dissolution may also trigger a patchy silica cementation within the inter-spherulite pore space. Finally, the release of $\mathrm{H}^{+}$by $\mathrm{Mg}$-clay leaching is possibly the origin of spherulite calcite dissolution and of moldic porosity (MV2 pore type) development. Another possible consequence of the stevensite dissolution is the excellent preservation of the pseudo-fenestral porosity that may have been favored by the release of water and related overpressure that mat have limited the effect of mechanical and chemical compaction. Patterns of pore network evolution and pore type genesis of spherulitic reservoirs are summarized in Figure 15.

Lower Cretaceous (Barremian-Aptian) shallow-water marine carbonates from Provence (SE

\section{France)}

Scenarios of diagenetic and pore network evolution of the Urgonian limestones from Provence have been proposed by Léonide et al. (2014) and Fournier et al. (2014). According to these interpretations, highly microporous limestones are considered to have developed as a result of micrite leaching and neomorphism in a meteoric shallow-burial setting probably during a. regional mid-Cretaceous (Albian-lower Cenomanian) subaerial exposure event. The resulting micrite microfabric consists of a poorly-packed euhedral/subhedral micrite showing intercrystalline and vuggy microporosity (MP2 micropore type: Figures 4 and 9 A, B, C). Later phases of meteoric (telogenetic?) dissolution induced corrosion and coalescence of micrite particles thus leading to the MP3 micropore type (Figures 4 and 9D). In contrast, after Léonide et al. (2014) porosity reduction in tight limestones is the result of an early marine and/or meteoric cementation of the intergranular macropores and intercrystalline micropores in matrix and micritized grains. Such processes led therefore to the development of the densely-packed, mosaic micrite microfabric and the corresponding MP1 micropore type. The intergranular pore 
type IG4 (Figures 4 and 9A) is the result of the partial occlusion of the intergranular space by an early isopacheous rim cement and by later sparry calcite cements formed during burial. Finally, the MV2 moldic pore type may have developed at two distinct stages of the diagenetic evolution: 1) aragonitic bioclasts were dissolved during early (intra-formational) subaerial exposure events and 2) micritized, microporous calcitic allochems were leached during later phases of meteoric diagenesis (telogenesis?). One can therefore regard the interparticle and vuggy microporosity in subrounded coalescent micrite (MP3 micropore type) from microporous peloidal grainstones as an intermediate pore type between the MP2 micropore type and the MV2 moldic pore type in response to calcite dissolution processes.

\section{Upper Cretaceous deep-water redeposited carbonates from the Gargano Peninsula (Italy)}

Although no detailed paragenesis of the Gargano limestones has been provided by previous authors (e.g. Hairabian et al., 2014), some analogies exist with the Urgonian limestones from Provence in terms of pore type genesis. The micropores types MP1, MP2 and MP3 have been recognized in both case studies. The tightly-packed intragranular micrites in cemented grainstones and associated MP1 micropore type (Figures 4 and 10 E) likely result from microcementation processes since micritized grains and micrite particle do not show evidence of mechanical and chemical compaction. The euhedral/subhedral nature of some microporous micrites (Figure 10 F) suggests that MP2 micropore type formed as a result of micrite neomorphism processes. The subrounded shape and the coalescence of micrite particles (Figure 10 G) clearly indicate that dissolution processes are the origin of the MP3 micropore type. This also support the interpretation of a secondary origin (matrix dissolution) for the intergranular pseudo-fenestral pore type IG3, since preserved patches of matrix always display MP3 microporosity in the corresponding samples observed under SEM. Finally, the pristine preservation of coccolithophorids together with the euhedral nature of micrite particles (Figure 
$10 \mathbf{H}$ ) are strongly indicative of an excellent preservation of a primary interparticle porosity (MP4 micropore type).

\section{Petroacoustic significance of the equivalent pore aspect ratio}

The detection of pore types from acoustic properties in highly diagenetically modified carbonates requires the definition of a petroacoustic index that would be dependent on pore network architecture only and that would be independent of pore volume and mineral composition. The equivalent pore aspect approach does not aim at determining a proxy of the actual geometry of pores, but at calculating the aspect ratio of an ideal spheroid that is acoustically equivalent with the actual pore network. A remarkable property of the equivalent pore aspect ratio derived from bulk modulus $\left(\alpha_{K}\right)$ is its lack of correlation with porosity for a given dominant pore type, for all of the identified dominant pore types and for all of the case studies investigated in the present work (Figure 12, 13 and 14). $\alpha_{K}$-porosity plots allow various domains of dominant pore types to be distinguished and the boundaries between such domains are independent of porosity. The compilation of $\alpha_{K}$ and porosity values for selected classes of pore types (Figure 16 and 17) leads to the same conclusion that $\alpha_{K}$ is a parameter that is not dependent on porosity and mineralogic composition and that displays relatively narrow and constant ranges of values that allow selected dominant pore type to be discriminated. Figures 16 and 17 also show the complexity of carbonate pore networks: intergranular and moldic pore types in $\alpha_{K}$-porosity are overlapping and the particular position would not always reveal the exact pore type but instead two optional pore types.

Another remarkable property of the equivalent pore aspect ratios is the lack of correlation between $\alpha_{K}$ and mineral composition. For example, in the spherulitic reservoir case study, regardless of the silica and dolomite volume fraction, $\alpha_{K}$ fits within the same range of values, 
from 0.12 to 0.2 for samples with dominant pseudo-fenestral pores (Figure 13C), and from 0.03 to 0.17 for samples with dominant intercrystalline porosity (Figure 13 D).

Figure 18 illustrates the interdependence of mineralogic and pore type effect on acoustic properties of carbonate reservoirs. In Brazilian pre-salt spherulitic reservoirs, dolomite-rich carbonates typically correspond to samples with dominant intercrystalline macroporosity (IC) and therefore with depleted $\alpha_{K}$ average value compared to samples with pseudo-fenestral pores (IG3). As a consequence, a sample with dominant IC pore type has a higher dolomite content and therefore a higher mineral bulk modulus compared to a pseudo-fenestral spherulitic limestone (IG3) but in the same time a lower $\alpha_{K}$. The opposite effect of both higher mineral bulk modulus (95 GPa for dolomite compared to $71 \mathrm{GPa}$ for calcite) and lower $\alpha_{K}$ results in an almost unchanging bulk modulus for the spherulitic reservoir at a fixed porosity. Such a combined impact of mineralogy and pore type probably largely explain why, in the bulk modulus-porosity plot for pre-salt spherulitic reservoirs (Figure 7 B), dolomite-rich samples cannot be separated from the calcite-rich samples.

As defined before, $\alpha_{K}$ is basically a parameter that allows quantifying the scattering of bulk moduli values at a given porosity. This parameters needs therefore to be compared with the dry pore space stiffness that is a well-known parameter in rock physics (Mavko et al., 1998). The dry pore space stiffness is representative of the stiffness of the whole pore network and is therefore dependent of the pore abundance and therefore of the pore volume. As highlighted by Mavko and Mukerji (1995), a constant pore shape is not equivalent to constant pore space stiffness thus illustrating the effect of elastic interaction (O'Connell and Budiansky, 1974). Indeed, a pore located in the neighborhood of many other pores is effectively softer than an isolated pore. This effect is illustrated in Figure 19A where bulk modulus-porosity relationships for constant aspect ratio (computed from DEM models of spheroidal inclusions) are compared with those calculated at constant dry pore stiffness. In addition, Figure 19B 
clearly shows that for a rock containing idealized spheroidal pores of a given aspect ratio, the dry pore stiffness significantly decrease with increasing porosity. In contrast, as discussed before, $\alpha_{K}$ is a parameter that is related to pore type and that is independent of pore volume. As a consequence, $\alpha_{K}$ should be regarded as being representative of the compressibility of individual pores. In addition, as illustrated by Figure 19C, the dry pore space stiffness also depends on the mineral content of the solid host: at a given porosity and for a given pore shape, the dry pore space stiffness is higher for a dolomitic host compared to a calcitic host. One consequence of the strong dependence of the dry pore space stiffness on porosity and mineralogy is its limited ability to discriminate pore type associations in contrast to $\alpha_{K}$, in the case of carbonate rocks with wide ranges of porosity and mineral composition such as the presalt spherulitic reservoirs (Figure 20 A) or the lower Cretaceous microporous limestones from Provence and Gargano (Figure 20 C).

The equivalent aspect ratio derived from the shear moduli appears to be also independent of porosity (Figures 12, 13 and 14) and mineralogy (Figure $13 \mathrm{D}$ and E). It generally displays narrower ranges of variation and has a variable potential for pore type discrimination. In the Urgonian and Gargano limestone case studies, similar pore type domains can be identified from both $\alpha_{K^{-}}$porosity and $\alpha_{\mu-}$ porosity plots (Figure 14). In contrast, for the pre-salt coquinas (Figure 12) and spherulitic reservoirs (Figure 13) the $\alpha_{\mu}$ parameter does not allow the various pore types to be distinguished. In a general way, samples with dominant intergranular and intercrystalline porosity together with samples dominated with microporosity show $\alpha_{\mu}$ values typically lower than 0.2 (Figures 12, 13 and 14). In contrast samples with dominant rounded moldic porosity exhibit a large range of $\alpha_{\mu}$ values (0.08 to 0.65$)$. In the samples from the Urgonian and Gargano limestones, where $\alpha_{\mu}$ values are typically high ( $>0.13$ and up to 0.65 ), moldic porosity is typically located in tightly cemented grainstones (Figures 9B and 11B). In contrast, in the pre-salt spherulitic and coquinas reservoirs, where $\alpha_{\mu}$ values are low to moderate 
(0.08-0.20), moldic porosity is commonly associated with preserved intergranular porosity (Figure 6 F) or intercrystalline porosity (Figure 8 F). The occurrence of well-connected interparticle micro-and macropores may therefore strongly lower the shear moduli and therefore the $\alpha_{\mu}$ values, even if present in minor proportions. As a consequence, while $\alpha_{K}$ appears to be mainly controlled by dominant pore types, $\alpha_{\mu}$ may be strongly influenced by the occurrence of quantitatively minor pore types.

\section{Depositional and diagenetic trends in $\alpha_{K}-$ porosity plots}

In pre-salt spherulitic reservoirs, an overall trend of $\alpha_{K}$ decrease with porosity decrease is visible (Figure 13A) whereas for a given pore type association there is no trend of changing $\alpha_{K}$ with porosity. Such an effect clearly indicates that in pre-salt spherulitic carbonates porosity changes are coupled with changes in pore types. The decrease in $\alpha_{K}$ is related to a transition from samples with dominant pseudo-fenestral (IG3) porosity to samples with dominant intercrystalline (IC) or intergranular porosity in densely-packed sediment (IG2). Decreasing trends of $\alpha_{K}$ with decreasing porosity in spherulitic reservoirs may be therefore related to an infill of the pseudo-fenestral pore space by dolomite rhombs and/or by an increase in spherulite grain packing.

In dominantly microporous carbonates, $\alpha_{K}$ - porosity relationships help quantifying the impact of diagenetic processes when changes in porosity are related to changes in pore structure. Low porosity $(0-7 \%)$ mosaic micrites (MP1 micropore type) result from cementation of the intercrystalline micropore space (Fournier et al., 2011) and correspond to low (0.05-0.16) $\alpha_{K}$ values. In contrast, intercrystalline and vuggy microporosity in euhedral/subhedral micritic medium (MP2 micropore type) developed by dissolution and neomorphism of a microporous micrite precursor, and is associated to higher porosity (6-21\%) and $\alpha_{K}$ values $(0.13-0.24)$. 
Finally, highly microporous subrounded/coalescent micrites with MP3 micropore types result from the dissolution of a calcitic micrite precursor with MP2 micropore type. The latter diagenetic transformation led to a significant increase in porosity (17-26\%) and moderate increase in $\alpha_{K}$. $\alpha_{K}$-porosity plots may be therefore used to detect selected diagenetic pathways (micro-cementation, neomorphism and leaching) affecting microporous carbonates from well logs if training datasets (e.g. integrated petrographic analysis and acoustic measurements from cores) are available.

\section{Pore type detection from acoustic data: relevance of the EPAR approach}

\section{Comparison with velocity-deviation methods (Anselmetti and Eberli, 1999)}

The variability of velocity values at a given porosity is known to reflect the different rockphysical signatures of pore types (Anselmetti and Eberli, 1993; Eberli et al., 2003). The velocity deviation log (Anselmetti and Eberli, 1999) which calculates the departure of the sonic velocity from the velocity predicted by the Wyllie time average equation (Wyllie et al., 1956) for a given porosity and mineralogy is used to quantify the variability of velocities at equal porosity and to predict pore types from well logs. The velocity deviation was shown to be zero for carbonates with poorly intergranular or intercrystalline porosity whereas positive deviations were revealed to be caused by stiff pores such as moldic or intra-fossil porosity. As illustrated in Figure 19 D for a purely calcitic rock, and for porosities ranging from 0 to $30 \%$, the P-wave velocity-porosity relationship predicted by the Wyllie time average equation is very close to the DEM models of oblate spheroidal pore inclusions for an almost constant aspect ratio (0.100.13). The results of the present database are therefore consistent with some of the findings of Anselmetti and Eberli (1999): 1) nearly spherical moldic pores (MV2) are characterized by high equivalent aspect ratios $\left(\alpha_{K}\right.$ typically $>0.15$ ) and correspond therefore to positive 
deviations; 2) intercrystalline macroporosity (IC), intercrystalline microporosity in mosaic micrite (MP1) and intergranular pores in coquinas (IG1) as well as in densely-packed spherulites (IG2) display low to moderate $\alpha_{K}$ values $(0.05-0.15)$ and display zero to negative deviation (Figure 20 B and 20 D). However, the main differences between the results from the present database and the Anselmetti and Eberli (1999) predictions are: 1) MP2, MP3 and MP4 micropore types correspond to significantly positive deviations (Figure 20 B), 2) pseudofenestral intergranular porosity (IG3) exhibit also highly positive deviations (Figure 20 D), and 3) moldic pores in flat-shaped bivalve coquinas (MV1) show negative deviations (Figure 20 F). These differences illustrate the large diversity of pore network structures and acoustic signatures within a given pore type class such as intergranular, moldic or intercrystalline. In addition, the velocity deviation can be used to predict pore types only for a given lithology and at a fixed porosity. Indeed, a major limitation of the deviation log approach is its strong dependence on porosity and mineralogy. For a given mineralogy (e.g. calcitic), velocity deviation values significantly vary with porosity changes (Figure 19 E). If one considers an idealized spheroidal pore of aspect ratio $>0.15$, the velocity deviation is very low at low porosity $(<10 \%)$ and become significantly positive $(>500 \mathrm{~m} / \mathrm{s}[1640 \mathrm{ft} / \mathrm{s}])$ at higher porosity. In addition, as illustrated in Figure 19 F, at a fixed porosity, and for a given pore shape (e.g. a spheroid with an aspect ratio of 0.15 ) velocity deviation is higher in dolostones compared to limestones. The overlap between velocity deviation in spherulitic reservoirs with high dolomite content (IC pore type) and those, dominantly calcitic, with pseudofenestral porosity (IG3 pore type) illustrates such a mineralogic dependence (Figure 20 B). As a consequence, the equivalent aspect ratios that are not dependent on porosity and mineralogy should provide more refined predictions of pore types in carbonates that the velocity deviation approach. 
The $\mathrm{Xu}$ and Payne (2009) approach has been proven to be a powerful method for the quantification of the pore shape effect on carbonate acoustic properties and for the inversion of pore type from acoustic measurements and seismic data (Zhao et al., 2013). In the model, the total pore volume is divided into four pore types: (1) clay-related pores, (2) interparticle pores, (3) microcracks, and (4) stiff pores. One limitation of the Xu-Payne approach is the difficulty to link such pre-defined pore types with actual pore networks and with petrographic/diagenetic features of carbonate rocks. In this approach, interparticle pores are considered as "reference pores" and are assumed to correspond to aspect ratios averaging 0.15 . Such a value is close to the narrow range of equivalent aspect ratios representing the time average equation $(0.10-0.13)$ in calcitic, silica and dolomite host and therefore to the reference pore definition of Anselmetti and Eberli (1999). In the present study, reference pores are defined as pores with equivalent aspect ratio $\alpha_{K}$ ranging from 0.10 and 0.15 in order to integrate the ranges of the velocity deviation and Xu-Payne approaches. As previously discussed, interparticle pores may actually include a wide range of pore structure and acoustic behaviour from soft (IG1, IG2) to stiff (IG4) pores (Figure 16). As a consequence, a correct use of the Xu-Payne approach requires an accurate petrographic/diagenetic definition of the so-called "reference-pores". According to $\mathrm{Xu}$ and Payne (2009), the reference line is assumed to model the Vp-porosity relationship for a rock containing only interparticle pores that are regarded as "reference pores". From the present database "reference pores" (i.e samples with equivalent aspect ratio around 0.15) could correspond to various actual pore types such as pseudo-fenestral pores (IG3) or micropores (MP1 and MP2). Samples with velocities above the reference line are considered to contain stiff pores that are modelled as spheroids with high aspect ratio and assumed to represent rounded molds or vugs. From our database such samples would represent carbonate rocks containing dominant rounded moldic pores or vugs (MV2) or also partially cemented intergranular pores (IG4). In contrast, samples with velocities below the reference line are 
considered to contain a mixture of reference pores and microcracks. As a consequence, flatshaped bivalve coquina reservoirs with preserved intergranular space (IG1) or with moldic pores (MV1) as well as spherulitic carbonates with dominant intercrystalline porosity (IC) or densely-packed intergranular porosity (IG2) might be misinterpreted as cracked-rocks. The EPAR and Xu-Payne approaches are therefore highly complementary if, for each carbonate case study, the petrographic/diagenetic nature and the corresponding equivalent aspect ratio of the reference pores and that of stiff and soft pore end-members are calibrated.

\section{Petroacoustic signature of carbonates: what kind of pore typing approach should we adopt?}

The detection of pore types from acoustic properties is highly dependent on the adopted pore type classification. As evidenced by Weger et al. (2009), the traditional Choquette and Pray (1970) classification is not suitable for discriminating properly pore types trends from velocityporosity relationships. The present database and the use of the equivalent aspect ratio approach have shown that a given Choquette and Pray pore type may include a variety of pore network structures and a wide range of acoustic signatures (Figure 16 and 17). For instance, the interparticle pore type class includes very soft pore networks (IG1 and IG2) but also very stiff pore spaces (IG4). The acoustic properties of carbonates with dominant microporosity have been commonly reported to be fairly well modelled by time average equation and such a pore type has been assumed to represent a reference pore type (Anselmetti and Eberli, 1999, Eberli et al., 2003; Weger et al., 2009). But if one considers the diversity of micropore structures that can be integrated within the definition of microporosity sensu Choquette and Pray (1970), more diverse acoustic behaviours can be observed. From the present study, only the intercrystalline microporosity in densely packed euhedral/subhedral micrite (MP1) can be regarded as a reference pore (equivalent aspect ratio ranging from 0.10 to 0.15 ). In contrast, mixed 
intercrystalline and vuggy microporosity (MP2 and MP3 micropore types) belong to the stiff pore domain. Finally, only rounded moldic pores (MV2) can be considered as stiff pores (pores with equivalent aspect ratio higher than 0.15 ), whereas moldic pores in flat-shaped bivalve coquinas (MV1) can be regarded as ranging from soft to reference pores.

As a consequence, in order to construct a pore type classification that is relevant for the detection of pore-related petroacoustic signatures in carbonates, a set of petrographic parameters that are believed to impact the acoustic properties of rocks must be integrated. In such an approach, the Choquette and Pray pore type classes represent a first order ranking in the proposed classification. As previously discussed, equivalent aspect ratios represent an index of the pore-related petroacoustic signature of carbonate rocks and are fundamentally controlled by the pore network architecture. For the interparticle pore type class, four main petrographic parameters to be integrated in the pore type classification are therefore identified: 1) grain shape, 2) grain contact, 3) grain packing and 4) nature of cements.

As evidenced for coquina reservoirs, the intergranular pores in poorly-cemented flat-shaped bivalve rudstones (IG1) are flat pores whose shape is obviously controlled by the morphology of the skeletal grains. The low equivalent aspect ratios $\alpha_{K}$ for IG1 pore type is related to the high compressibility of such flat pores. Low $\alpha_{K}$ values for IG2 pore types are interpreted to result from the very narrow pore space located between densely-packed spherulites and additionally to local calcite dissolution at the sutured grain contact. Equivalent aspect ratio $\alpha_{K}$ in secondary pseudo-fenestral pores (IG3) ranges from reference pore values $(0.10-0.15)$ to stiff pore values (above 0.15). Such a variability is interpreted to result from different dominant grain contacts: pseudofenestral spherulitic reservoirs are stiffer for dominantly long grain contacts and softer for point contacts. In addition, the relatively loose packing of spherulite is the origin of the formation of relatively large and equant pores (pseudo-fenestral pores) after stevensite dissolution thus enhancing the stiffness of such an intergranular pore space. Finally, 
the isopacheous and drusy calcite cementation around grains significantly stiffen the contact between grains and tends also to form equant pores in the center of the intergranular pores (IG4). Both of these parameters enhance the stiffness of the intergranular pores and therefore favor high $\alpha_{K}$ values. In contrast, patchy cementation has no significant effect on the equivalent aspect ratio since it doesn't modify the pore network structures of the residual pores in noncemented area. In Figure $\mathbf{2 1}$ are summarized the main factors controlling the acoustic signature of intergranular pores and their effect on the equivalent aspect ratio $\alpha_{K}$.

Similarly, three dominant factors are interpreted to affect the acoustic signature of micropores: 1) morphology, 2) packing and 3) coalescence of micrite particles. As discussed by Fournier et al. (2011), euhedral micrite microfabrics favor the development of flat, narrow and therefore compressible intercrystalline micropores between the plane crystal faces, particularly in the case of a dense packing of micrite particles (mosaic micrite). Subhedral to subrounded micrite microfabrics may be regarded as reference pores by analogy with intergranular macroporosity in poorly consolidated sands. The development of secondary microvugs within micrite matrix or micritized grains leads to the apparition of larger, equant pores thus enhancing the stiffness of such a micropore network. In addition, micrite coalescence tends to stiffen the contact between micrite particles and therefore to increase the micropore space stiffness.

Finally, from the present study, the shape of dissolved allochems (from flat-shaped to nearly spherical) appears to represent the dominant control on the acoustic signature of moldic pores.

\section{CONCLUSION}

An extensive database of laboratory and subsurface acoustic measurements coupled with a detailed petrographic analysis of carbonate rock samples provided new insights into the acoustic signature of pore types in carbonate reservoirs from various depositional and diagenetic 
settings. The equivalent pore aspect ratio appears to be a relevant method for quantifying the pore type effect on acoustic properties of carbonate rocks and for the detection of pore types from porosity and acoustic measurements:

1) The equivalent aspect ratio derived from the bulk modulus $\left(\alpha_{K}\right)$ can be regarded as a proxy of the stiffness of individual pores and is independent of the density of pores and of the solid host mineralogy.

2) The $\alpha_{K}$ is controlled by the pore network and solid network architectures.

3) The independence of $\alpha_{K}$ with regard to porosity and mineralogy makes this approach a relevant tool for detecting pore types in carbonates reservoirs with wide ranges of porosity values and mineralogic compositions.

The present work revealed that the terms "reference pores" as well as "stiff pores" and "soft pores/microcracks" may represent a large variety of actual pore types. A major recommendation regarding petroacoustic modelling in carbonates is therefore to calibrate, for each case study, the petrographic/diagenetic nature and the corresponding equivalent aspect ratio of the reference pores and of the stiff and soft pore domains.

Finally, the success of pore type detection methods appears to be highly dependent on the adopted pore type classification. The Choquette and Pray (1970) pore types include a too large variety of pore network structures to be correctly discriminated from acoustic and porosity data.

The present study shows that the quantification of the pore type effect on acoustic properties requires a pore type classification that includes additional petrographic parameters such as grain and/or pore shape, nature of grain contact, occurrence and nature of cements, packing of particles (allochems and/or crystals). Further challenges in the EPAR approach will be 1) to 
determine the microstructural factors impacting the $\alpha_{\mu}$ parameter, 2) to integrate NMR and CT scan analyses (pore size distribution and pore shapes) in order to quantitatively support the descriptive pore type classification and 3) to test the applicability of the proposed pore type detection approach for seismic data.

\section{REFERENCES}

Abrahão, D., and J.E. Warme, 1990. Lacustrine and associated deposits in a rifted continental margin-Lower Cretaceous Lagoa Feia Formation, Campos basin, Offshore Brazil, in B.J. Katz, ed., Lacustrine Basin Exploration-Case Studies and Modern Analogs: AAPG Memoir 50. AAPG, Tulsa, Oklahoma, USA, p. 287-305.

Anselmetti, F.S., and G.P. Eberli, 1993, Controls on sonic velocity in carbonates: Pure and Applied Geophysics, v. 141, p. 287-323.

Anselmetti, F.S., and G.P. Eberli, 1999, The Velocity-Deviation Log: A Tool to Predict Pore Type and Permeability Trends in Carbonate Drill Holes from Sonic and Porosity or Density Logs: AAPG Bulletin, v. 83, no. 3, p. 450-466.

Anselmetti, F.S., and G.P. Eberli, 2001, Sonic velocity in carbonates - a combined product of depositional lithology and diagenetic alteration, in R.N. Ginsburg, ed., Subsurface Geology of 
a Prograding Carbonate Platform Margin, Great Bahama Bank: Results of the Bahamas Drilling Project, SEPM Special Publication, v. 70, p. 193-216.

Anselmetti, F.S., G.A. von Salis, K.J. Cunningham, and G.P. Eberli, 1997, Acoustic properties of Neogene carbonates and siliciclastics from the subsurface of the Florida Keys: implications for seismic reflectivity: Marine Geology, v. 144, p. 9-31.

Bertani, R.T., and A.V. Carozzi, 1985. Lagoa Feia Formation (Lower Cretaceous), Campos Basin, Offshore Brazil: Rift Valley Stage Lacustrine Carbonate Reservoirs — I: Journal of Petroleum Geology, v. 8, no. 1, p. 37-58.

Borgomano J., 2000. The Upper Cretaceous carbonates of the Gargano-Murge region, southern Italy: A model of platform-to-basin transition: AAPG Bulletin, v. 84, p. 1561-1588.

Borgomano, J., J.P. Masse, M. Fenerci-Masse, and F. Fournier, 2013, Petrophysics of Lower Cretaceous platform carbonate outcrops in Provence (SE France): implications for carbonate reservoir characterisation: Journal of Petroleum Geology, v. 36, no. 1, p. 5-42.

Buckley, J.P., D. Bosence, and C. Elders, 2015, Tectonic setting and stratigraphic architecture of an Early Cretaceous lacustrine carbonate platform, Sugar Loaf High, Santos Basin, Brazil, in D.W.J. Bosence, K.A. Gibbons, D.P. Le Heron, W.A. Morgan, T. Pritchard, and B.A. Vining, 
eds., Microbial Carbonates in Space and Time: Implications for Global Exploration and Production. Geological Society, London, Special Publications, v. 418, p. 175-191.

Carminatti, M., J.L. Dias, and B. Wolff, 2009, From turbidites to carbonates: breaking paradigms in deep waters, in Offshore Technology Conference, Houston, TX, 4-7 May 2009, OTC 20124.

Carvalho, M. D., U.M. Praca, A.C. Silva-Telles, R.J. Jahnert, and J.L. Dias, 2000, Bioclastic carbonate lacustrine facies models in the Campos Basin (Lower Cretaceous), Brazil, in E.H. Gierlowski-Kordesch, and K.R. Kelts, eds., Lake Basins Through Space and Time. American Association of Petroleum Geologists, Tulsa, OK, Studies in Geology, v. 46, p. 245-256.

Cleary, M.P., I.W. Chen, and S.M. Lee, 1980, Self-consistent techniques for heterogeneous media: American Society of Civil Engineering and Mechanics, v. 106, p. 861-887.

Choquette, P. W., and L. C. Pray, 1970, Geologic nomenclature and classification of porosity in sedimentary carbonates: AAPG Bulletin, v. 54, p. 207-250.

Eberli, G. P., G. T. Baechle, F. S. Anselmetti, and M. L. Incze, 2003, Factors controlling elastic properties in carbonate sediments and rocks: The Leading Edge, v. 22, p. 654-660. 
Fournier, F. and J. Borgomano, 2007, Geological significance of seismic reflections and imaging of the reservoir architecturein the Malampaya gas field (Philippines): AAPG Bulletin, v. 91 , no. 2 , p. $235-258$.

Fournier, F. and J. Borgomano, 2009, Critical porosity and elastic properties of microporous mixed carbonate-siliciclastic rocks: Geophysics, v. 74, no. 2, p. 93-109.

Fournier, F., P. Leonide, K. Biscarrat, A. Gallois, J. Borgomano, and A. Foubert, 2011, Elastic properties of microporous cemented grainstones: Geophysics, v. 76, p. 211-226.

Fournier, F., P. Léonide, L. Kleipool, R. Toullec, J.J.G. Reijmer, J. Borgomano, T. Klootwijk, and J. Van Der Molen, 2014, Pore space evolution and elastic properties of platform carbonates (Urgonian limestone, Barremian-Aptian, SE France): Sedimentary Geology, v. 308, p. 1-17.

Funiciello, R., P. Montone, M. Parotto, F. Salvini, and M. Tozzi, 1991, Geodynamical evolution of an intra-orogenic foreland: the Apulia case history (Italy): Bollettino della Società Geologica Italiana, v. 110, p. 419-425.

Gassmann, F., 1951, Über die Elastizität Poröser Medien: Veierteljahrsschrift der Naturforschenden Gesellschaft in Zürich, v. 96, p. 1-23.

Hairabian, A., F. Fournier, J. Borgomano, and S. Nardon, 2014, Depositional facies, pore types and elastic properties of deep-water gravity flow carbonates: Journal of Petroleum Geology, v. 
37, no. 3, p. 231-250.

Hashin, Z. and S. Shtrikman, 1963, A variational approach to the elastic behavior of multiphase materials: Journal of the Mechanics and Physics of Solids, v. 11, p.127-140.

Kenter, J. A. M., F. F. Podladchikov, M. Reinders, S. J. Van der Gaast, B.W. Fouke, and M. D. Sonnenfeld, 1997, Parameters controlling sonic velocities in a mixed carbonate-siliciclastics Permian shelf margin (Upper San Andres Formation, Last Chance Canyon, New Mexico): Geophysics, v. 62, p. 505-520.

Kenter, J. A. M., H. Braaksma, K. Verwer, and X. M. T. van Lanen, 2007, Acoustic behavior of sedimentary rocks: Geological properties versus Poisson's ratios: The Leading Edge, v. 26, p. $436-444$.

Léonide, P., F. Fournier, J.J.G. Reijmer, H. Vonhof, J. Borgomano, J. Dijk, M. Rosenthal, M., van Goethem, 2014, Diagenetic patterns and pore space distribution along a platform to outershelf transect: Sedimentary Geology, v. 306, p. 1-23.

Masse, J.P., 1993, Valanginian-Early Aptian carbonate platforms from Provence, Southeastern France, in J.A.T. Simo, R.W. Scott and J.P. Masse, eds, Cretaceous carbonate platforms: AAPG Memoir, v. 56, p. 363-374. 
Masse J.P., and J. Borgomano, 1987, Un modèle de transition plate-forme - bassin carbonatés contrôlé par des phénomènes tectoniques : le Crétacé du Gargano (Italie Méridionale) : Comptes Rendus de l'Académie des Sciences de Paris, v. 304, p. 521-526.

Mavko, G. and T. Mukerji, 1995, Seismic pore space compressibility and Gassmann's relation: Geophysics, v. 60, no. 6, p. 1743-1749.

Mavko, G., T. Mukerji, and J. Dvorkin, 1998, The rock physics handbook: tool for seismic analysis in porous media. Cambridge University Press.

McHargue, T.R., 1990, Stratigraphic development of proto-South Atlantic rifting in Cabinda, Angola - A petroliferous lake basin, in B.J. Katz, ed., Lacustrine Basin Exploration-Case Studies and Modern Analogs: AAPG Memoir, v. 50, p. 307-326.

Moreira, J. L. P., C.V. Madeira, J.A. Gil, and M.A.P. Machado, 2007, Bacia de Santos: Boletim de Geociencas da Petrobras, v. 15, p. 531-549.

Norris, A.N., 1985, A differential scheme for the effective moduli of composites: Mechanics of Materials, v. 4, p. 1-16.

O’Connell, R. and B. Budiansky, 1974, Seismic velocities in dry and saturated cracked solids: Journal of Geophysical Research, v. 82, p. 5719-5736. 
Rafavich, F., C.H. St. C. Kendall, and T.P. Todd, 1984, The Relationship between Acoustic Properties and the Petrographic Character of Carbonate Rocks: Geophysics, v. 49, p. 16221636.

Saleh, A.A. and J.P. Castagna, 2004, Revisiting the Wyllie time average equation in the case of near-spherical pores: Geophysics, v. 69, no. 1, p. 45-55.

Thomson, D.L., J.D. Stilwel, and M. Hall, 2015, Lacustrine carbonate reservoirs from Early Cretaceous rift lakes of Western Gondwana: Pre-Salt coquinas of Brazil and West Africa: Gondwana Research, v. 28, p. 26-51.

Tosca, N.J. and V.P. Wright, 2015, Diagenetic pathways linked to labile Mg-clays in lacustrine carbonate reservoirs: a model for the origin of secondary porosity in the Cretaceous pre-salt Barra Velha Formation, offshore Brazil, in P.J. Armitage, A.R. Butcher, J.M. Churchill, A.E. Csoma, C. Hollis, R.H. Lander, J.E. Omma, and R.H. Worden, eds., Reservoir Quality of Clastic and Carbonate Rocks: Analysis, Modelling and Prediction: Geological Society, London, Special Publications, v. 435, SP435-1.

Verwer, K., H. Braaksma, and J.A.M. Kenter, 2008, Acoustic properties of carbonates: Effects of rock texture and implications for fluid substitution: Geophysics, v. 73, no. 2, B51-B65. 
Weger, R. J., G. T. Baechle, G. P. Eberli, J. L. Massaferro, and Y. F. Sun, 2009, Quantification of pore structure and its effect on sonic velocity and permeability in carbonates: AAPG Bulletin, v. 93 , p. $1297-1317$.

Wright, V. P. and A. Barnett, 2015, An abiotic model for the development of textures in some South Atlantic early Cretaceous lacustrine carbonates, in D. W. J. Bosence, K.A. Gibbons, D.P. Le Heron, W.A. Morgan, T. Pritchard, and B.A. Vining, eds., Microbial Carbonates in Space and Time: Implications for Global Exploration and Production: Geological Society, London, Special Publications, v. 418, p. 209-219.

Wyllie, M. R., A. R. Gregory, and G. H. F. Gardner, 1956, Elastic wave velocities in heterogeneous and porous media: Geophysics, v. 21, no. 1, p. 41-70.

Xu, S. and M.A. Payne, 2009, Modelling elastic properties in carbonate rocks: The Leading Edge, v. 28, p. 66-74.

Zhao, L., M. Nasser, and D. Han, 2013, Quantitative geophysical pore-type classification and its geological implication in carbonate reservoirs: Geophysical Prospecting, v. 61, p. 827-841.

Zimmerman, 1991, Compressibility of sandstones: Elsevier. 


\section{Figure captions:}

Figure 1: Chronostratigraphic framework of the Lower Cretaceous deposits from offshore Brazil (after Moreira et al., 2007).

Figure 2: A: Location map of Urgonian limestone outcrops and sampling localities in SE France (after Fournier et al., 2014); B: Geological setting Gargano peninsula, Italy (after Hairabian et al., 2014); C: Lithostratigraphic column of Upper Cretaceous carbonates from the Gargano base-of-slope domain.

Figure 3: Principles of the Equivalent Pore Aspect Ratio approach.

Figure 4: Summary of the descriptive pore type classification.

Figure 5: Pre-salt coquina samples (offshore Brazil): A: Definition of lithological classes; B: dry bulk modulus-porosity plot; C: dry bulk modulus-porosity plot.

Figure 6: Brazilian pre-salt coquinas (offshore Brazil). A: Blue-epoxy and alizarin stained thin-section photomicrographs under plane-polarized light of a bivalve rudstone showing one phase of isopachous rim of silica cement $(s)$ around grains and a phase of blocky sparry calcite cement $(\boldsymbol{c})$; B: Same view as A under crossed-polarized light. C: Blue-epoxy and alizarin stained thin section photomicrograph under natural light of a cemented bivalve rudstone with a 
reworked silicified intraclast (intra.). The silicified intraclast is also composed of a bivalve grainstone/rudstone. The interskeletal pore space is entirely filled with sparry calcite cements (c) whereas a large proportion of the bioclasts are leached $(\boldsymbol{m})$; D: Blue-epoxy stained thin section photomicrograph under natural light of a poorly cemented bivalve rudstone with wellpreserved interskeletal porosity (IG1 pore type) while mechanical and chemical compaction features are lacking; E: Blue-epoxy stained thin section photomicrograph under natural light of a tighly cemented bivalve rudstone showing a significant development of moldic porosity (MV1 pore type: $\boldsymbol{m}$ ); F: Blue-epoxy and alizarin stained thin-section photomicrographs under plane-polarized light of a skeletal grainstone/rudstone composed of subrounded, pieces of bivalves. The interskeletal pore space is entirely occluded by sparry calcite cements $(\boldsymbol{c})$ whereas a large proportion of the skeletal grains are leached (MV2 pore type: $\boldsymbol{m}$ ). Scarce dolomite rhombs $(\boldsymbol{d})$ are present within moldic pores.

Figure 7: Pre-salt spherulitic samples (offshore Brazil): A: Definition of lithological classes; B: dry bulk modulus-porosity plot; C: dry bulk modulus-porosity plot.

Figure 8: Brazilian pre-salt spherulitic reservoirs (offshore Brazil). A: Blue-epoxy stained thin-section photomicrographs under natural light of a spherulitic sand (spherulites: $\mathbf{s p h}$.) with leached matrix (black arrow: relicts of clay matrix) and secondary intergranular porosity (IG3 pore type: sip); B: Blue-epoxy stained thin-section photomicrographs under natural light of a densely-packed spherulitic sand (spherulites: sph.) showing a narrow (secondary) intergranular pore space (IG3 pore type); C: Blue-epoxy and alizarin stained thin-section photomicrographs under crossed-polarized light of a spherulitic sand (spherulites: sph.) whose intergranular pore space is filled with dolomite rhombs $(\boldsymbol{d})$. A significant intercrystalline porosity (IC pore type) 
occurs between dolomite rhombs; D: Blue-epoxy and alizarin stained thin-section photomicrographs under plane-polarized light of a spherulitic sand (spherulites: sph.) with dolomite rhombs $(\boldsymbol{d})$ infilling the intergranular pore space. Within the intergranular space, thread-shaped corrugated pores (ICb pore type: $\boldsymbol{t} \boldsymbol{p}$ ) are present and may represent molds of leached clay laminae; E: Blue-epoxy and alizarin stained thin-section photomicrographs under plane-polarized light of a spherulitic sand (spherulites: sph.) with dolomite rhombs $(\boldsymbol{d})$ infilling the intergranular pore space and patches of silica cements $(\boldsymbol{s})$; F: Blue-epoxy stained thinsection photomicrographs under natural light of a spherulitic sand (spherulites: sph.) with intergranular dolomite rhombs $(\boldsymbol{d})$ showing significant leaching of some spherulites (MV2 pore type: $m)$.

Figure 9: Blue-epoxy stained thin-section photomicrographs under plane-polarized light of Urgonian limestones (Barremian-Aptian) from Mont-de-Vaucluse area, Provence (SE France), showing the main pore type associations. A: IG4 pore type: well-sorted skeletal grainstone showing the partial occlusion of the intergranular pore space by a first phase of isopachous rim cement and by a poorly developed, second phase of sparry calcite. B: wellsorted skeletal grainstone (Caramanica Fm.) showing leached bioclasts (moldic macroporosity) and sparry calcite cement occluding the intergranular pore space. C: wellsorted peloidal grainstone with microporous micritized grains and sparry calcite cement occluding the intergranular pore space.

Figure 10: A-D: SEM photographs of Urgonian limestone samples from Provence (SE France). A: micritized grain (peloid) surrounded by sparry calcite cements (sp) and showing loosely-packed micrite particles, vugular pores (white arrows) and intercrystalline 
microporosity (MP2 micropore type); B: close-up of A showing the euhedral morphology of the micrite particles, the vuggy micropores (white arrows) and the intercrystalline microporosity (MP2 micropore type); C: MP3 micropore type: microporous micritized grain (peloid) showing coalescent/subrounded micrite (black arrows) and vuggy micropores (white arrows); D: detail of coalescent, subrounded micrite particles. E-H: SEM photographs of the Upper Cretaceous limestones from the Gargano Peninsula (Italy). E: MP1 micropore type: low porosity, densely-packed euhedral/subhedral (=mosaic) micrite; F: MP3 micropore type: highly porous subhedral to subrounded/coalescent micrite (incipient coalescence of micrite particles: black arrows) associated with intercrystalline and vuggy (white arrows) microporosity; G: detail of coalescent, subrounded micrite particles; H: MP4 micropore type: highly porous euhedral micrite with relicts of coccolithophorids (white arrows).

Figure 11: Blue-epoxy stained thin-section photomicrographs under plane-polarized light of Upper Cretaceous base-of-slope limestones from the Gargano Peninsula (Italy), showing the main pore type associations. A: well sorted packstone/grainstone (Nevarra Fm.) with partially dissolved micrite matrix and resulting secondary (pseudo-fenestral) intergranular porosity (black arrow). Significant microporosity may exist within the partially preserved matrix (white arrow); B: poorly sorted skeletal grainstone (Caramanica Fm.) showing leached bioclasts (moldic macroporosity) and sparry calcite cement occluding the intergranular pore space. C: Microporous mudstone (Nevarra Fm.) with fragments of planktonic Foraminifera.

Figure 12: Pre-salt coquina facies (offshore Brazil): A: Equivalent pore aspect ratio calculated from well-log-derived bulk modulus $\left(\alpha_{\mathrm{K}}\right)$, as a function of porosity; B: Equivalent 
pore aspect ratio calculated from well-log-derived shear modulus $\left(\alpha_{\mu}\right)$, as a function of porosity. C: $\alpha_{\mathrm{K}}-\alpha_{\mu}$ plot. Samples are labelled as a function of dominant pore type.

Figure 13: Pre-salt spherulitic facies (offshore Brazil): A: Equivalent pore aspect ratio calculated from well-log-derived bulk modulus $\left(\alpha_{K}\right)$, as a function of porosity; $\mathbf{C}: \alpha_{K}-\alpha_{\mu}$ plot. B: Equivalent pore aspect ratio calculated from well-log-derived shear modulus $\left(\alpha_{\mu}\right)$, as a function of porosity; D: $\alpha_{\mathrm{K}}$ and $\alpha_{\mu}$ plotted as a function of silica and dolomite volume fraction for samples with dominant pseudo-fenestral pores (IG3); E: $\alpha_{\mathrm{K}}$ and $\alpha_{\mu}$ plotted as a function of silica and dolomite volume fraction for samples with dominant intercrystalline pore type (IC). Samples are labelled as a function of dominant pore type.

Figure 14: A, B and C: Lower Cretaceous shallow-water marine carbonates (Urgonian platform, Provence, France): A: Equivalent pore aspect ratio calculated from well-logderived bulk modulus $\left(\alpha_{\mathrm{K}}\right)$, as a function of porosity; B: Equivalent pore aspect ratio calculated from well-log-derived shear modulus $\left(\alpha_{\mu}\right)$, as a function of porosity. $\mathbf{C}: \alpha_{\mathrm{K}}-\alpha_{\mu}$ plot. Samples are labelled as a function of dominant pore type. D, E and F: Upper Cretaceous deep-water redeposited limestones (Gargano Peninsula, Italy): D: Equivalent pore aspect ratio calculated from well-log-derived bulk modulus $\left(\alpha_{K}\right)$, as a function of porosity; E: Equivalent pore aspect ratio calculated from well-log-derived shear modulus $\left(\alpha_{\mu}\right)$, as a function of porosity. F: $\alpha_{\mathrm{K}}-\alpha_{\mu}$ plot. Samples are labelled as a function of dominant pore type.

Figure 15: Synthesis of the diagenetic transformations affecting in-situ spherulitic facies (Lower Cretaceous, Santos Basin, offshore Brazil) and resulting dominant pore types. A: 
diagenetic and pore space evolution from an initial Mg-clay with sparse spherulites; B: diagenetic and pore space evolution from an initial Mg-clay with densely-packed spherulites.

Figure 16: Synthesis of the acoustic signature of intergranular pores, (Brazilian pre-salt, Urgonian limestone and Gargano limestone). A: $\alpha_{\mathrm{K}}$-porosity plot, samples are labelled as a function of dominant pore type; B: Histograms of $\alpha_{\mathrm{K}}$ values for the distinct intergranular pore types.

Figure 17: Synthesis of the acoustic signature of microporosity and moldic porosity (Brazilian pre-salt, Urgonian limestone and Gargano limestone). A: $\alpha_{K}$-porosity plot for microporous samples, samples are labelled as a function of dominant micropore type; $\mathbf{B}$ : Histograms of $\alpha_{\mathrm{K}}$ values for the distinct micropore types; $\mathbf{C}$ : $\alpha_{\mathrm{K}}$-porosity plot for samples with moldic porosity, samples are labelled as a function of dominant pore type; $\mathbf{D}$ : Histograms of $\alpha_{K}$ values for the distinct moldic pore types;

Figure 18: A: DEM bulk modulus models for a homogeneous solid host of various mineralogic compositions containing dry spheroidal inclusions ( $\alpha$ : aspect ratio of the spheroid). Brazilian pre-salt carbonate samples with pseudofenestral (IG3) and intercrystalline (IC) dominant pore types are reported on the bulk modulus-porosity plot. The overlap between pseudo-fenestral domain (grey area) and intercrystalline domain (dashed area) is related to a combined impact of mineralogy and pore compressibility; B: histograms of $\alpha_{K}$ values for carbonate samples from the Brazilian pre-salt, dominated by IG3 and IC pore types. 
Figure 19: A: Comparison between dry bulk modulus-porosity relationships computed for constant spheroid aspect ratio $\alpha$ (DEM models) and for constant dry pore space stiffness; B: Dry pore space stiffness plotted as a function of porosity for a calcitic rock containing spheroidal inclusions of various aspect ratio $\alpha$; computation are based on a DEM approach. Note the decreasing trend of dry pore stiffness with increasing porosity, regardless of the pore aspect ratio; C: Dry pore space stiffness plotted as a function of porosity for a rock of various mineralogical compositions and containing spheroidal pores of constant aspect ratio $\alpha=0.15$. D: P-wave velocity plotted as a function of porosity for a calcitic rock containing brinesaturated spheroidal pores of various aspect ratio $\alpha$ (DEM models: full) and compared with the time average equation. Note that up to a porosity of $30 \%$, the time average equation approximates DEM models for spheroidal inclusions of aspect ratio ranging from 0.10 to 0.15 . E: P-wave velocity deviation plotted as a function of porosity for a calcitic rock containing spheroidal inclusions of various aspect ratio $\alpha$; computation are based on a DEM approach. Note the significant increase in velocity deviation with increasing porosity for pore aspect ratios higher than 0.15 and lower than $0.10 ; \mathbf{F}$ : P-wave velocity deviation plotted as a function of porosity for a rock of various mineralogical compositions and containing spheroidal pores of constant aspect ratio $\alpha=0.15$.

Figure 20: A: Crossplot of dry pore stiffness and porosity for samples with dominant intercrystalline or intergranular macropores; B: Crossplot of $\mathrm{P}-$ wave velocity deviation and porosity for samples with dominant intercrystalline or intergranular macropores; C: Crossplot of dry pore stiffness and porosity for microporous samples; $\mathbf{D}$ : Crossplot of $\mathrm{P}$-wave velocity deviation and porosity for microporous samples; $\mathbf{E}$ : Crossplot of dry pore stiffness and porosity 
for samples with dominant moldic macropores; F: Crossplot of $\mathrm{P}-$ wave velocity deviation and porosity for samples with dominant moldic macropores.

Figure 21: Impact of selected petrographic parameters (grain shape, grain packing, grain contact, cements) on $\alpha_{\mathrm{K}}$ for carbonates with dominant intergranular porosity and link with pore type classification. 
Figure 1

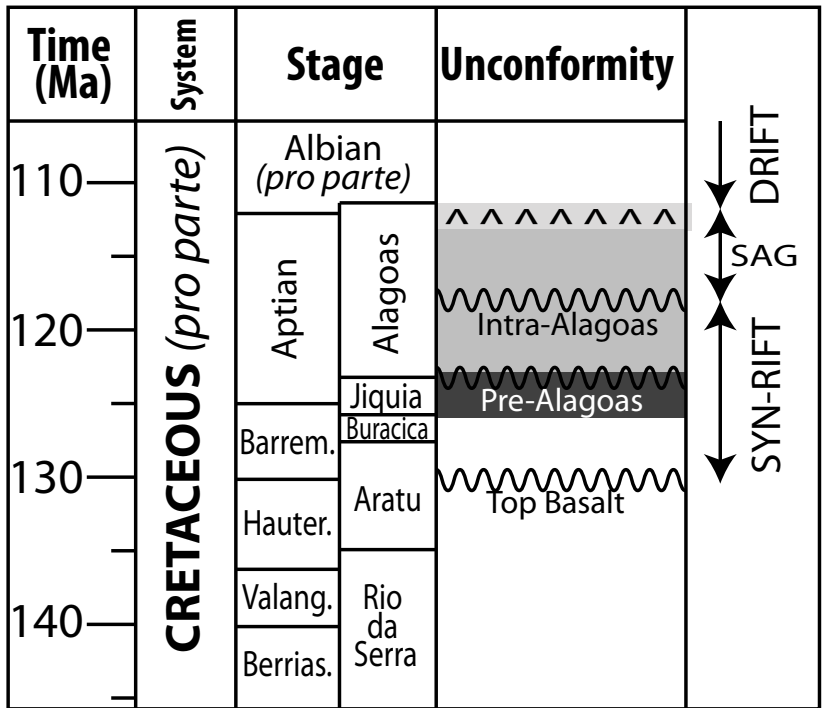

$\wedge \wedge \wedge \wedge$ Evaporite deposits

Main occurences of spherulitic / shrub facies

Main occurences of coquina facies 
Figure 2

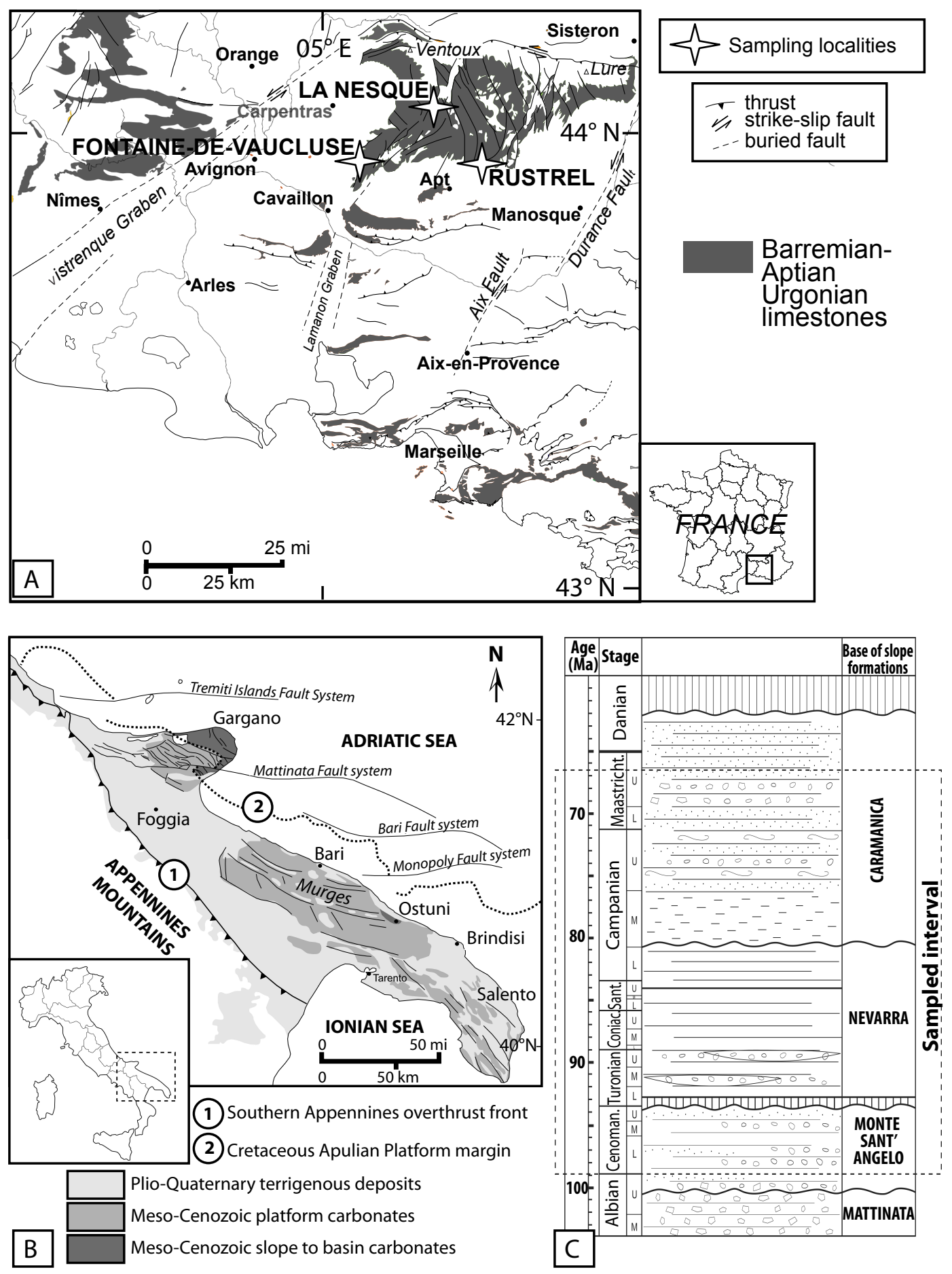


Figure 3

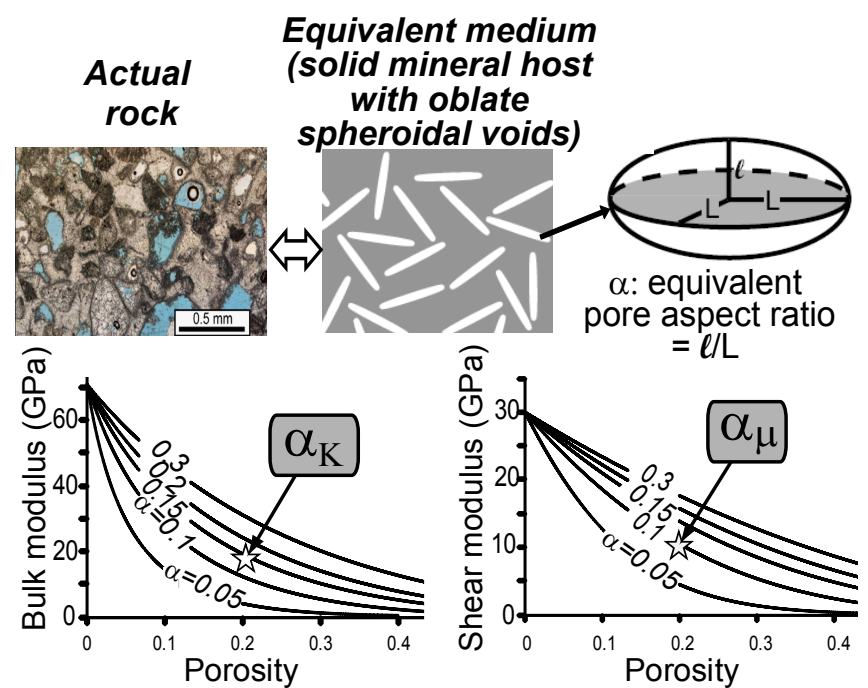


Figure 4
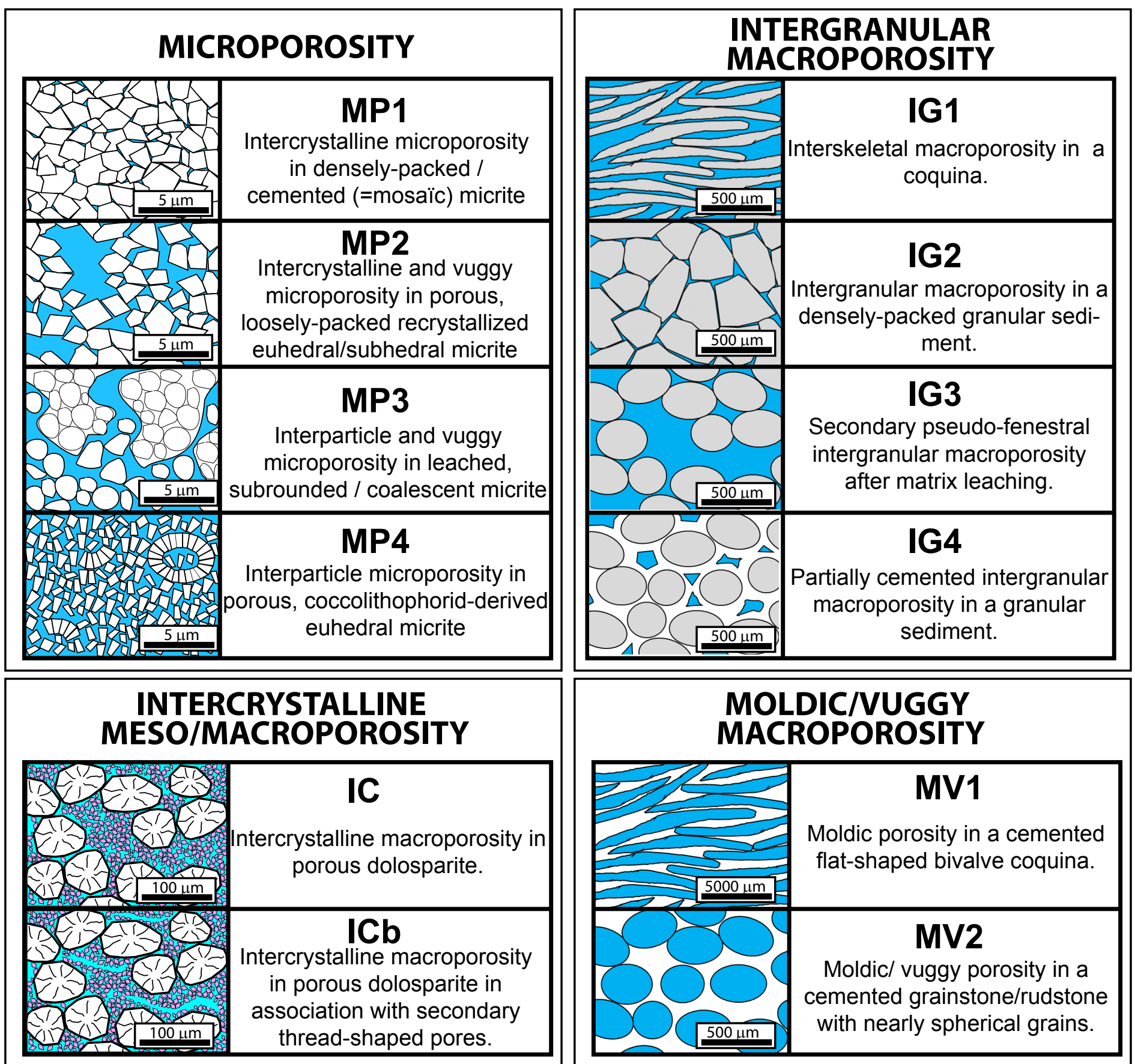
Figure 5

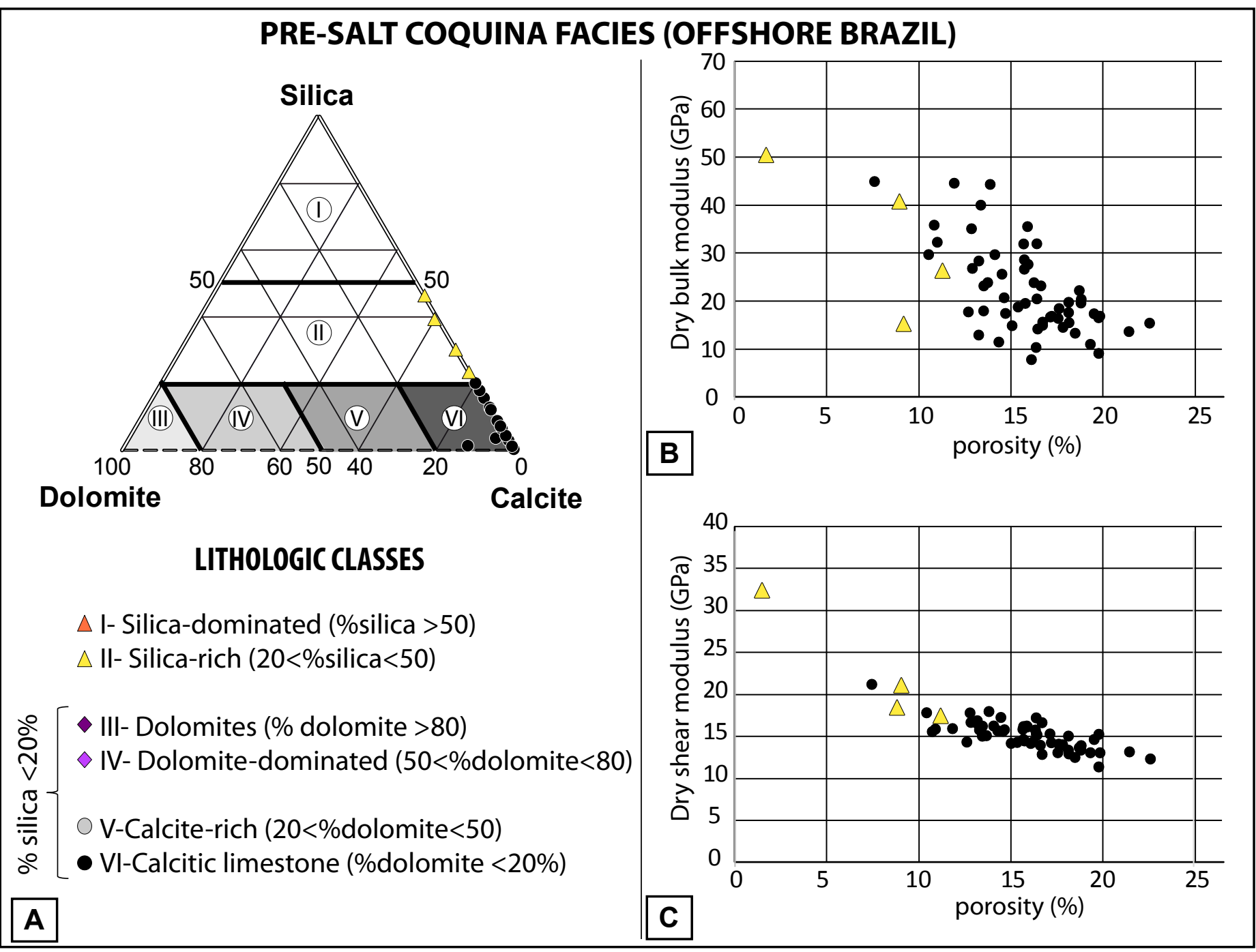


Figure 6
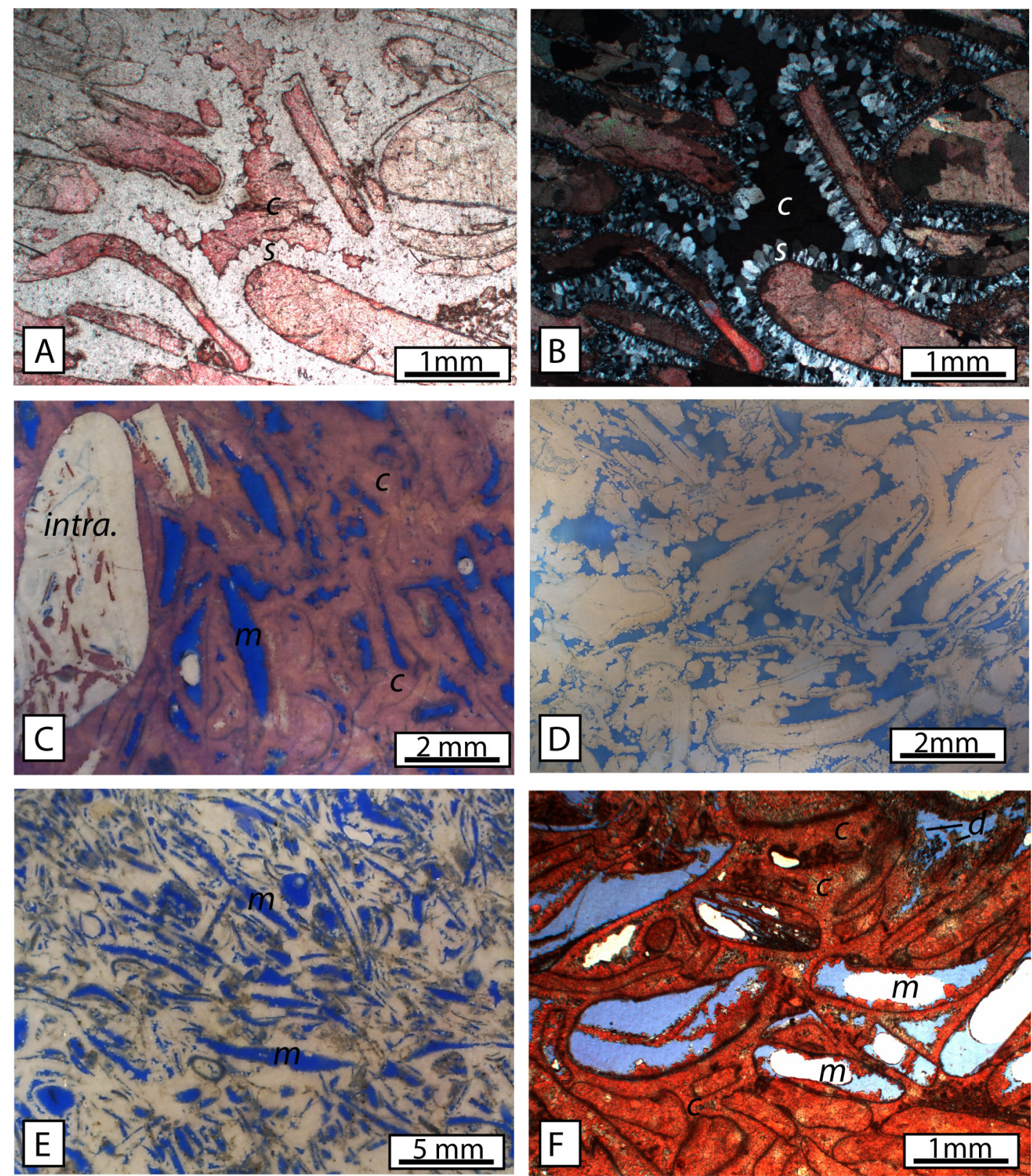
Figure 7

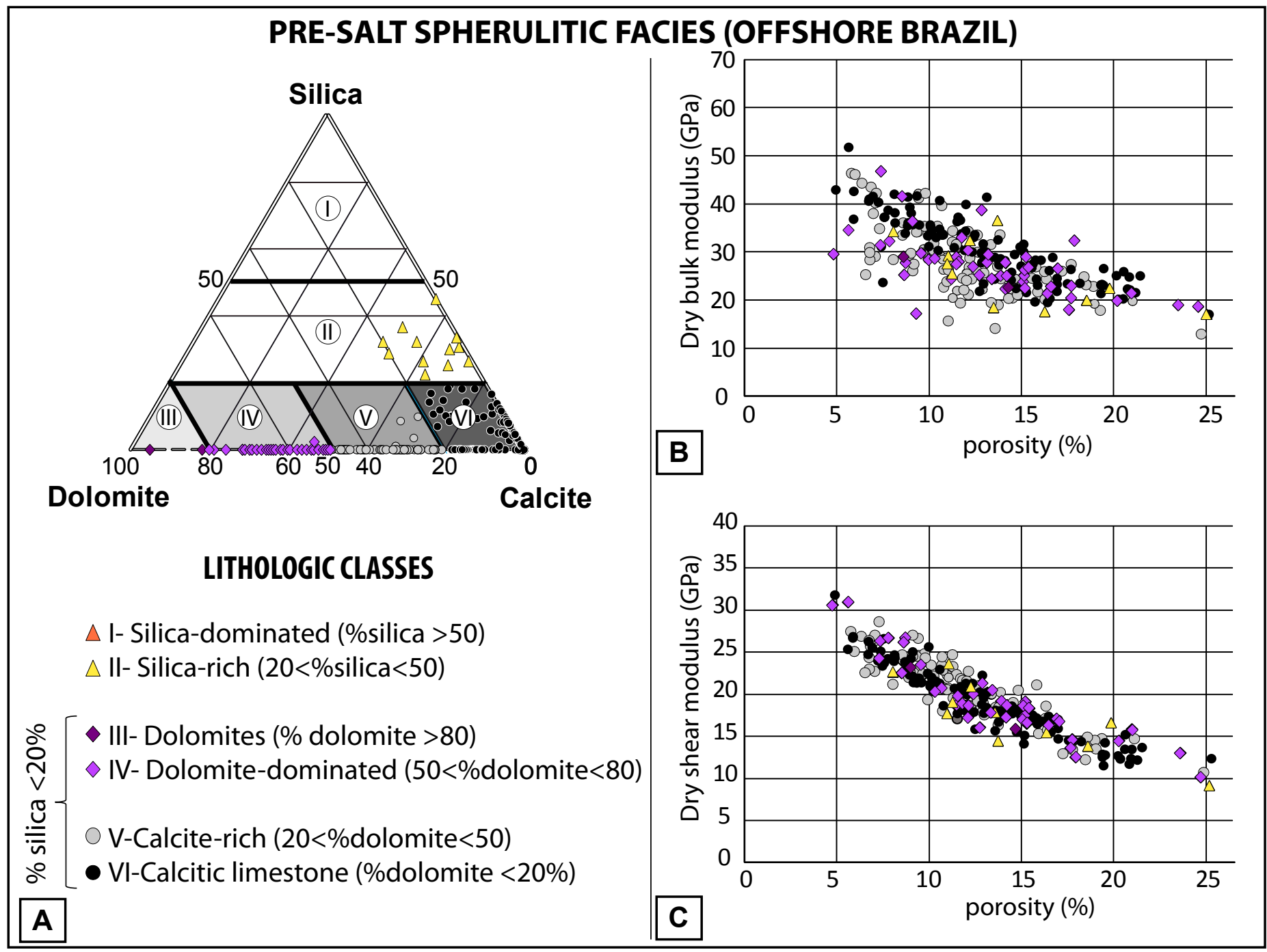


Figure 8
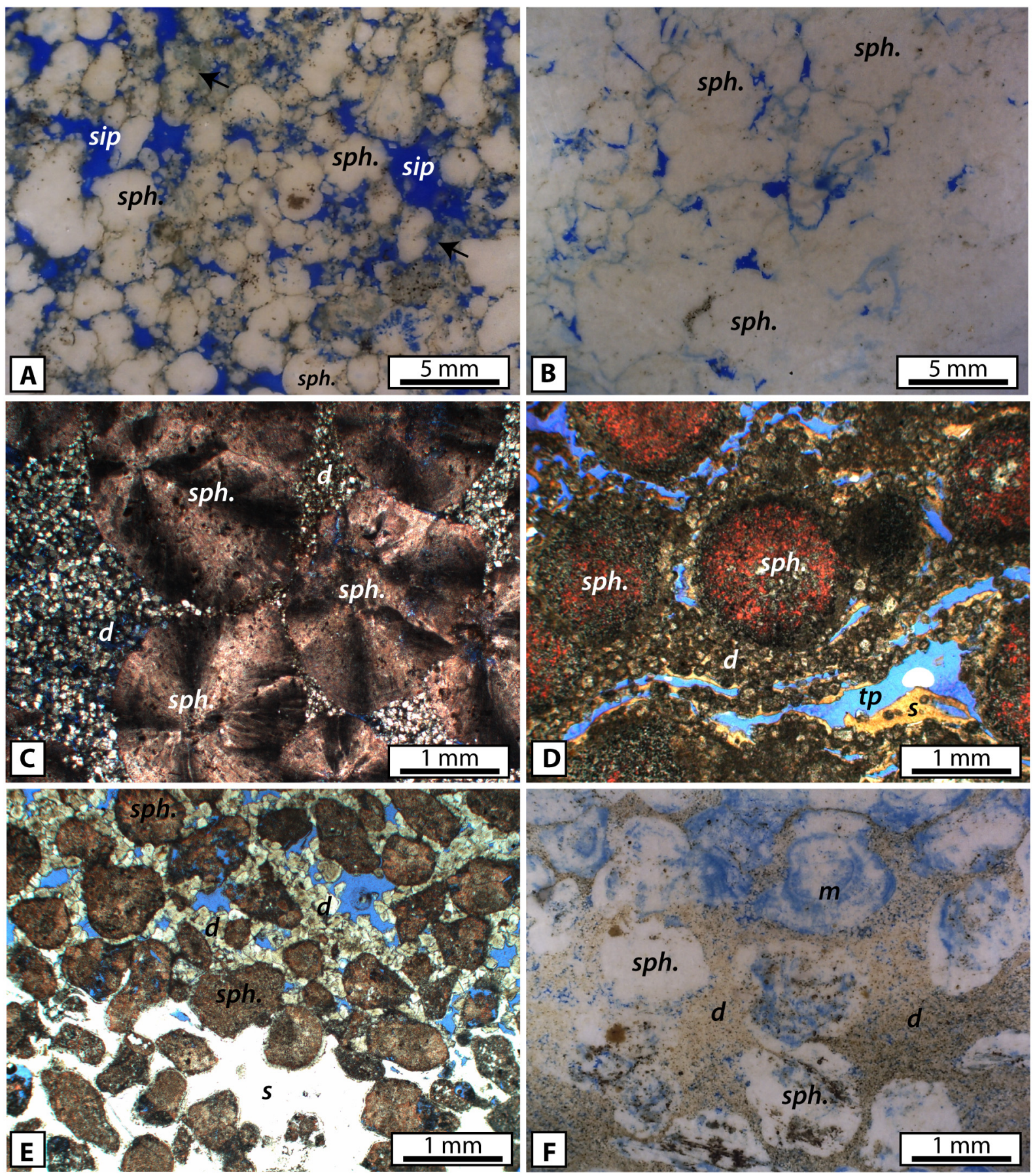
Figure 9
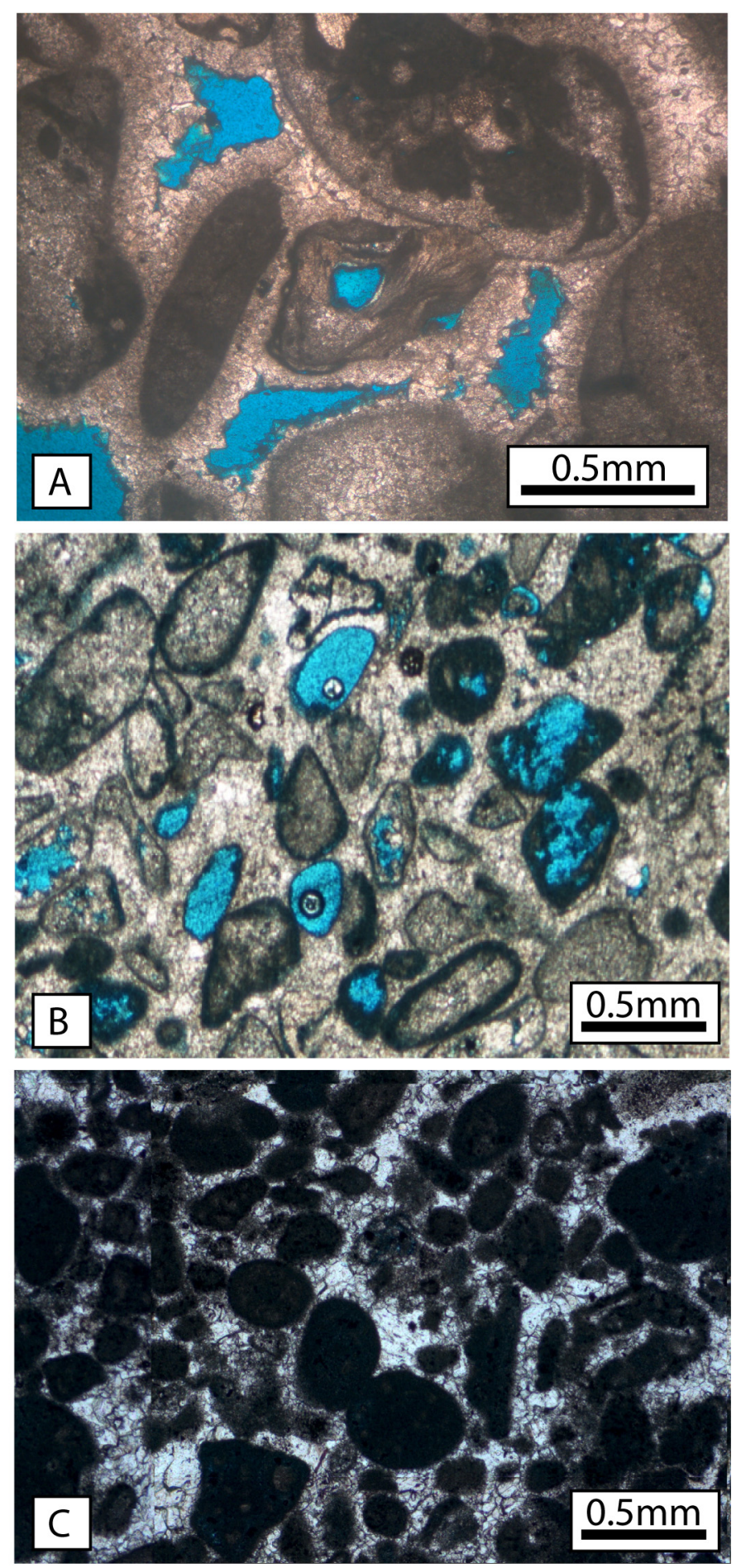
Figure 10
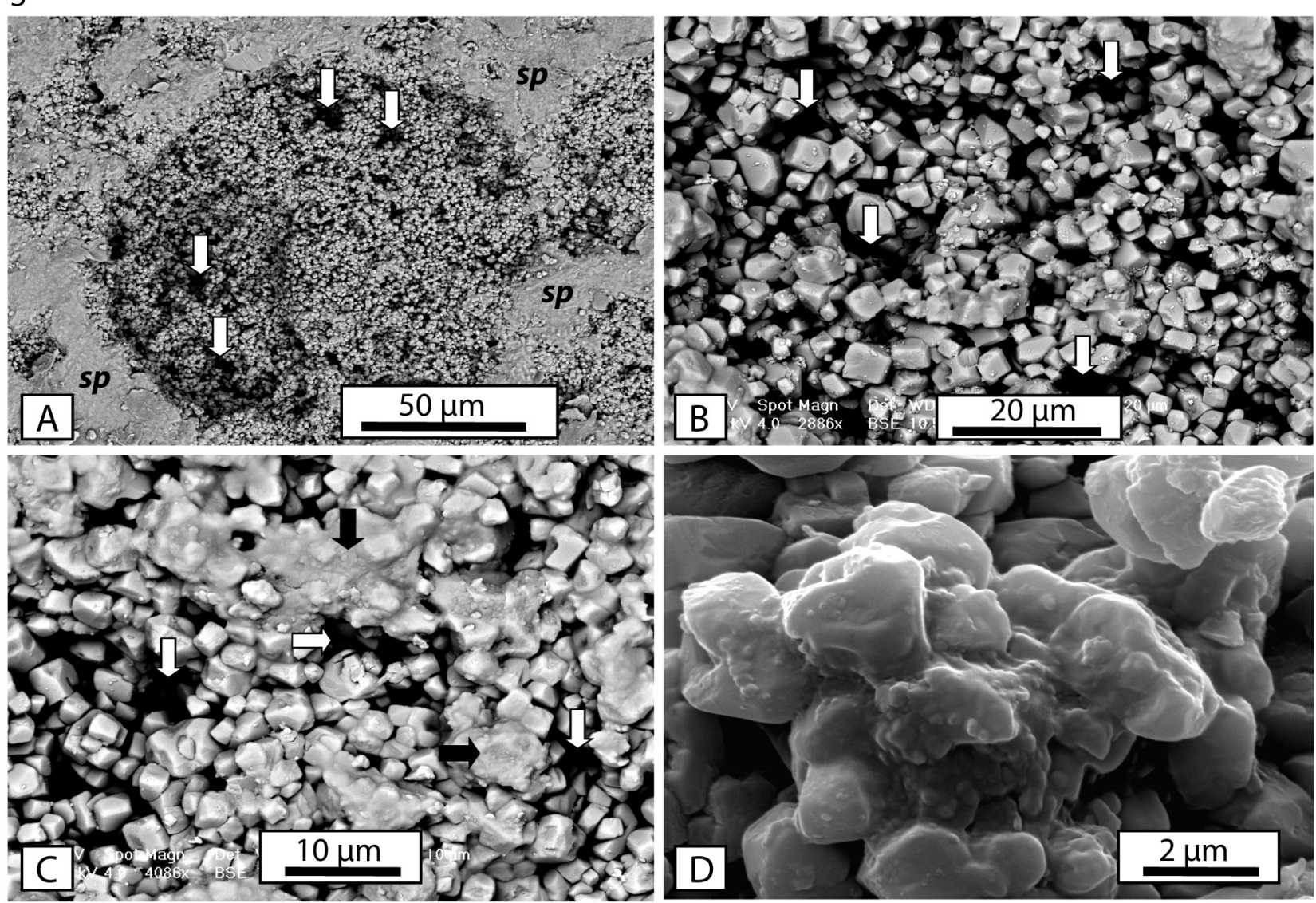

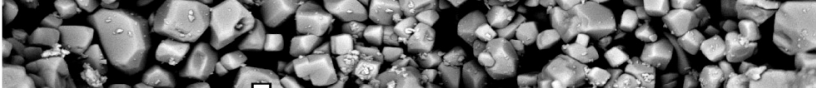

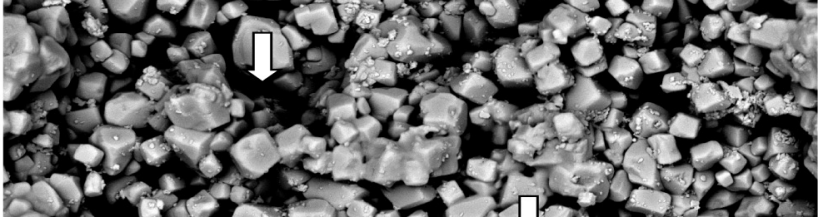

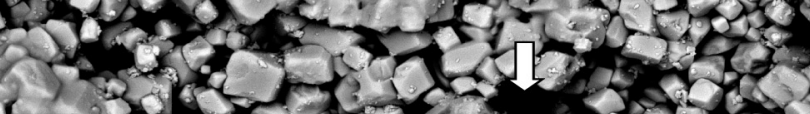

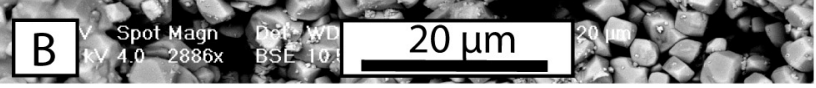
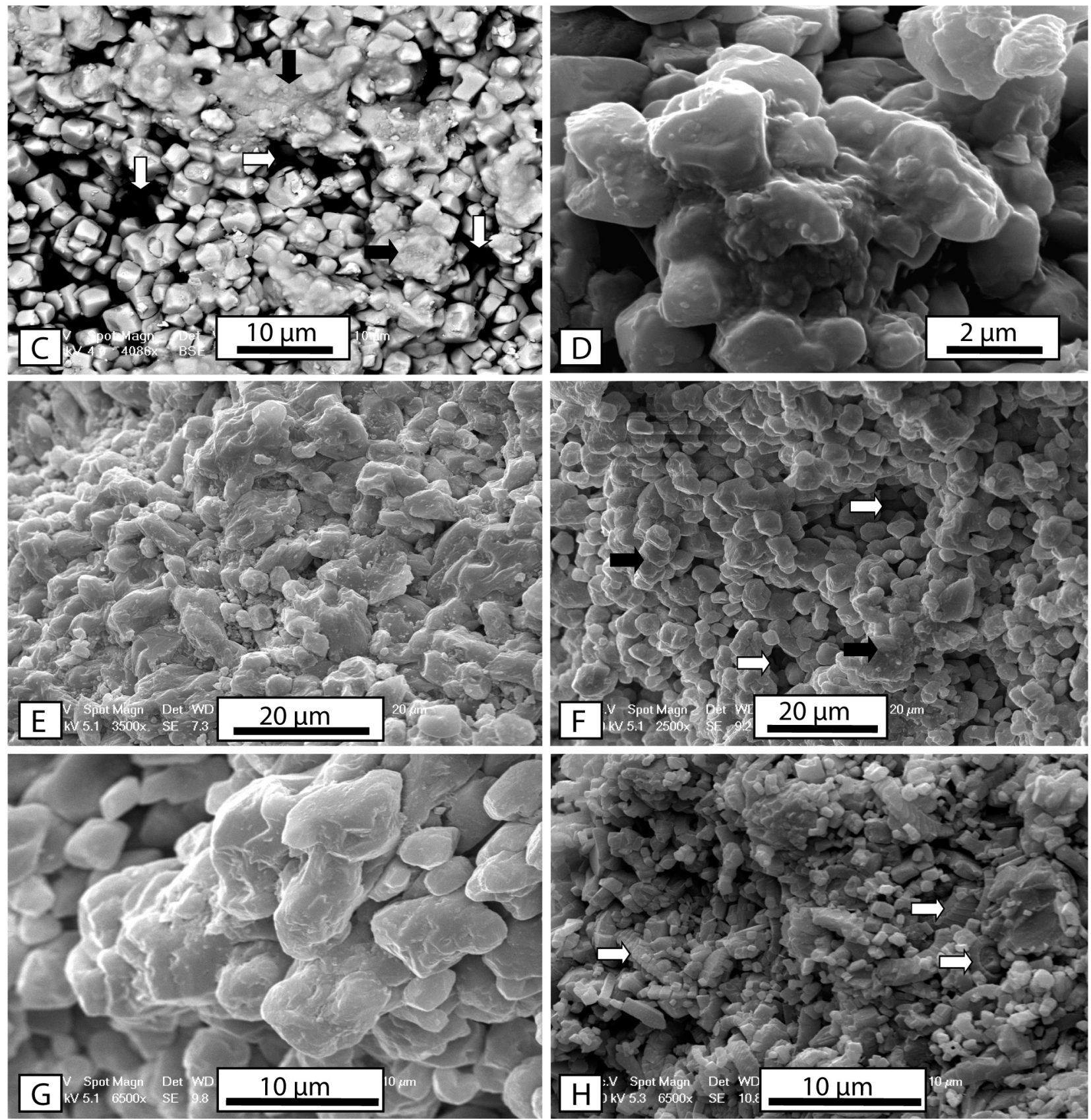
Figure 11
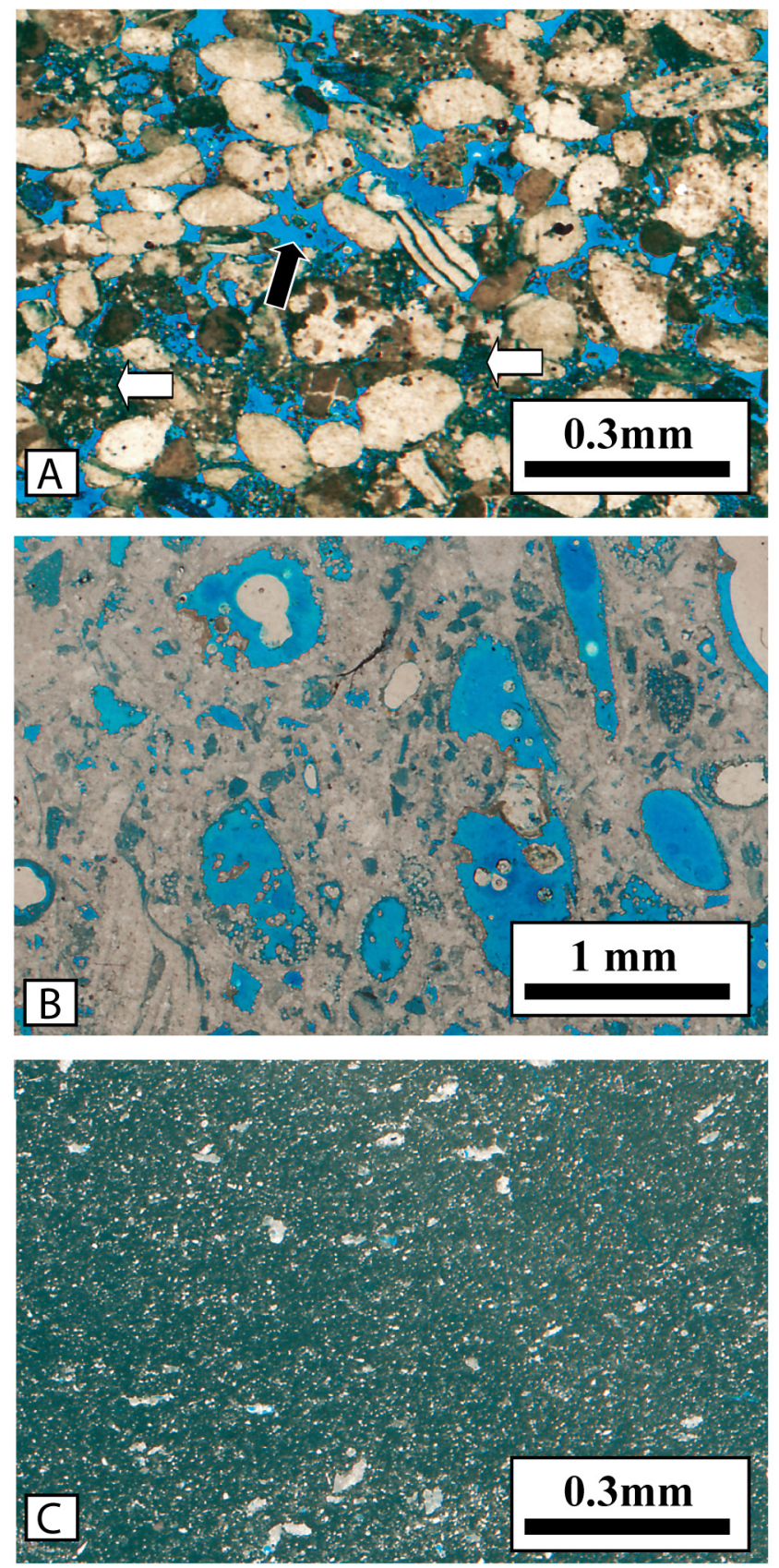
Figure 12

PRE-SALT COQUINA FACIES (OFFSHORE BRAZIL)

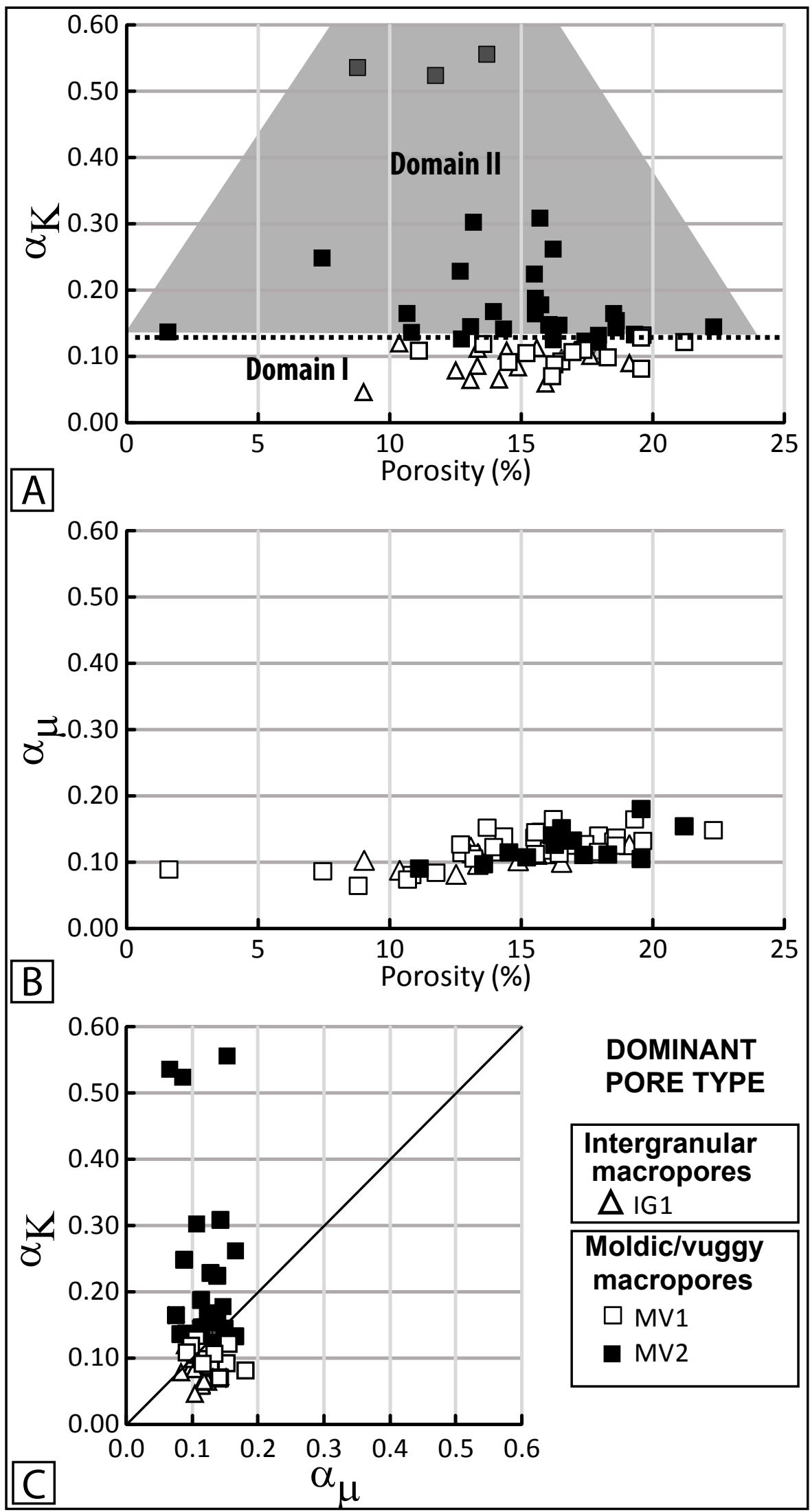


Figure 13

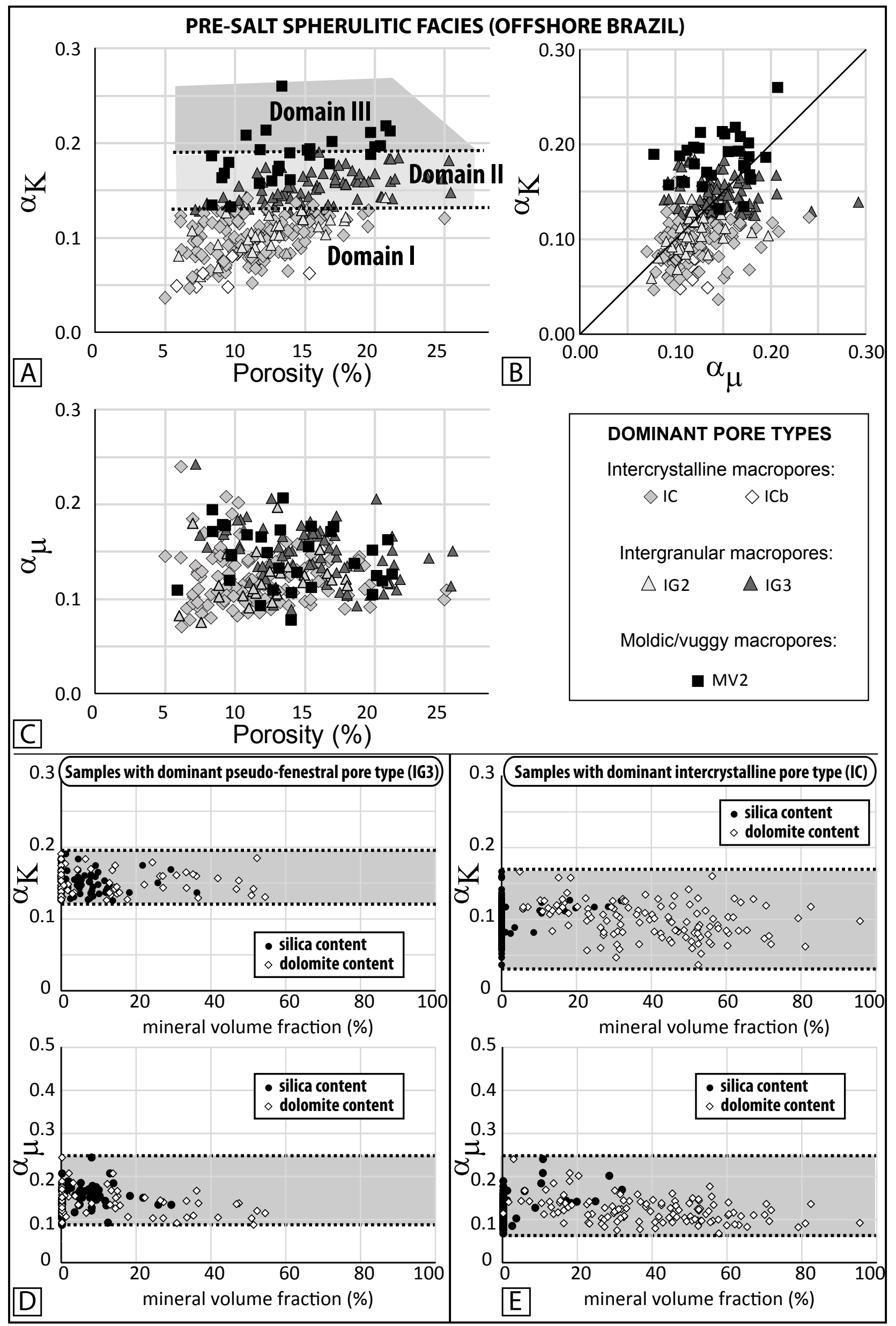


Figure 14

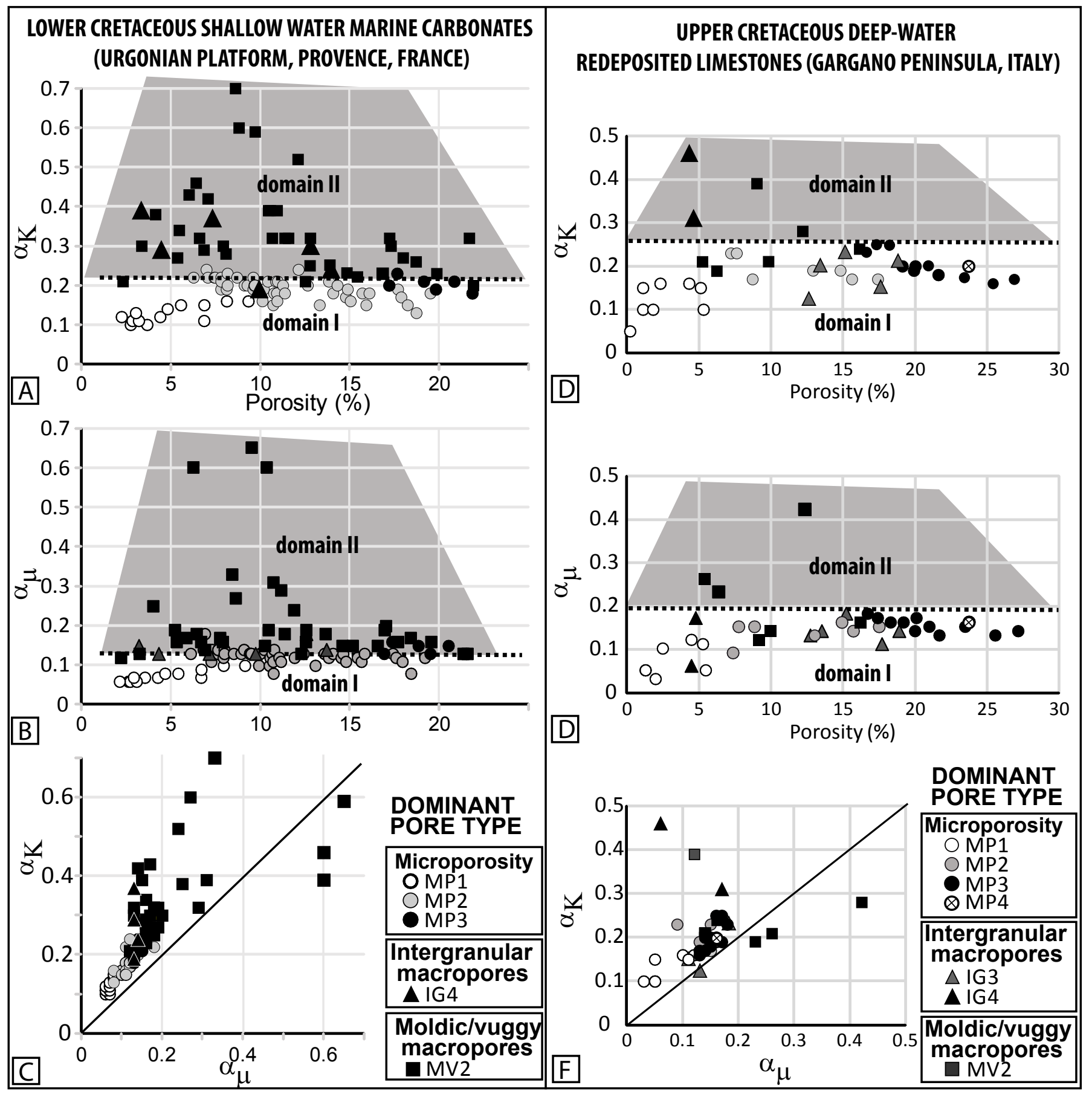




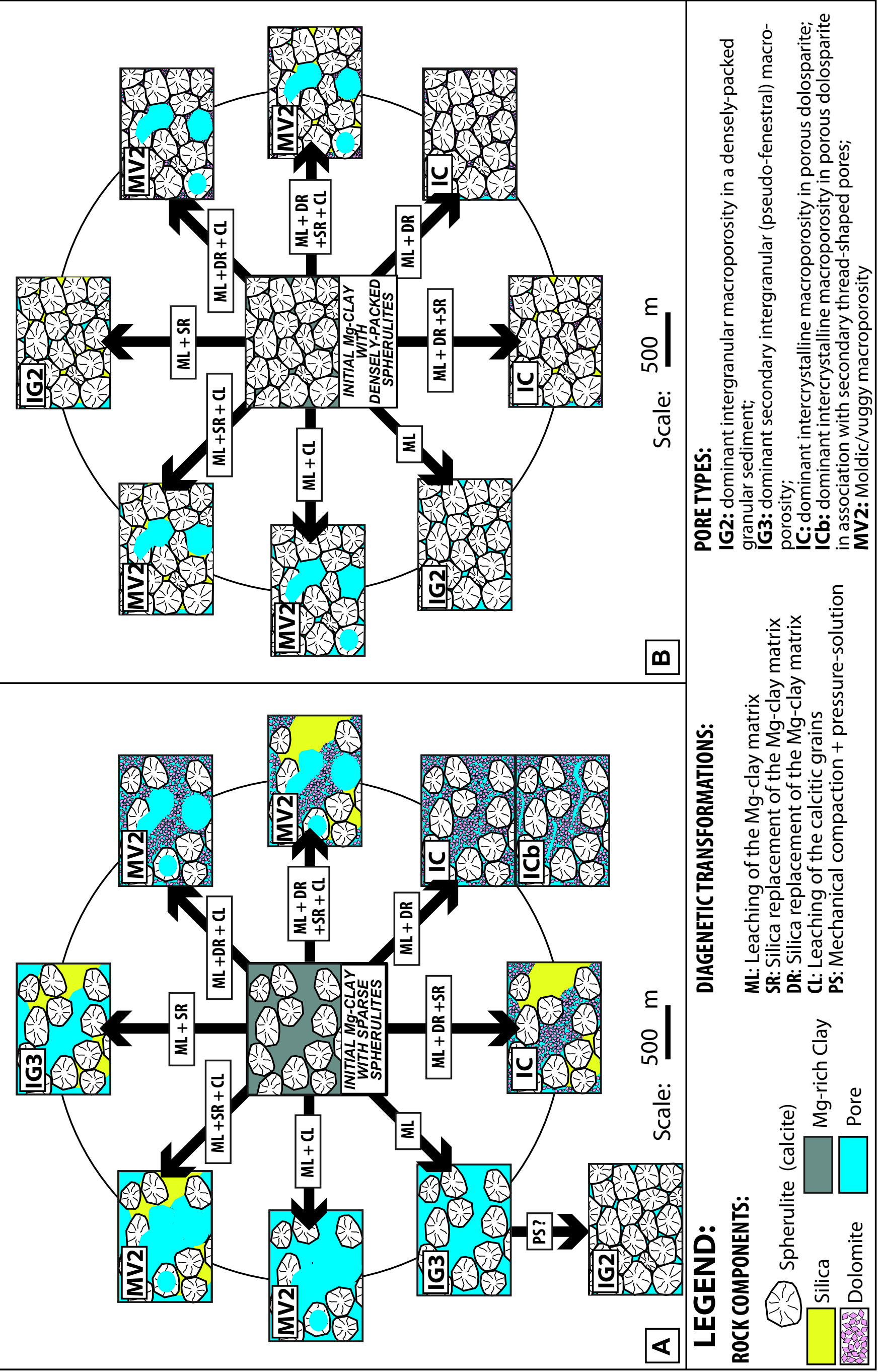


Figure 16
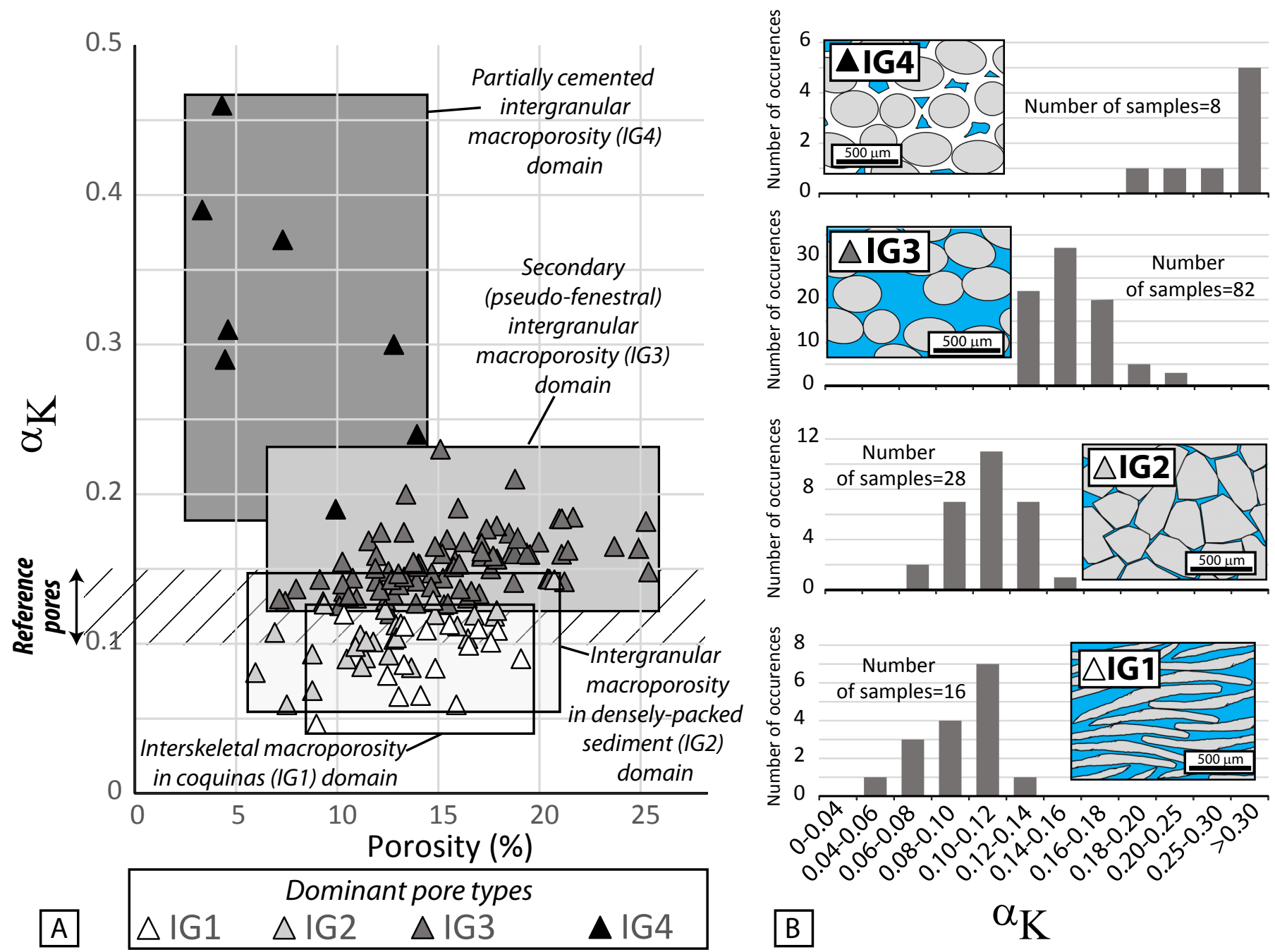
Figure 17
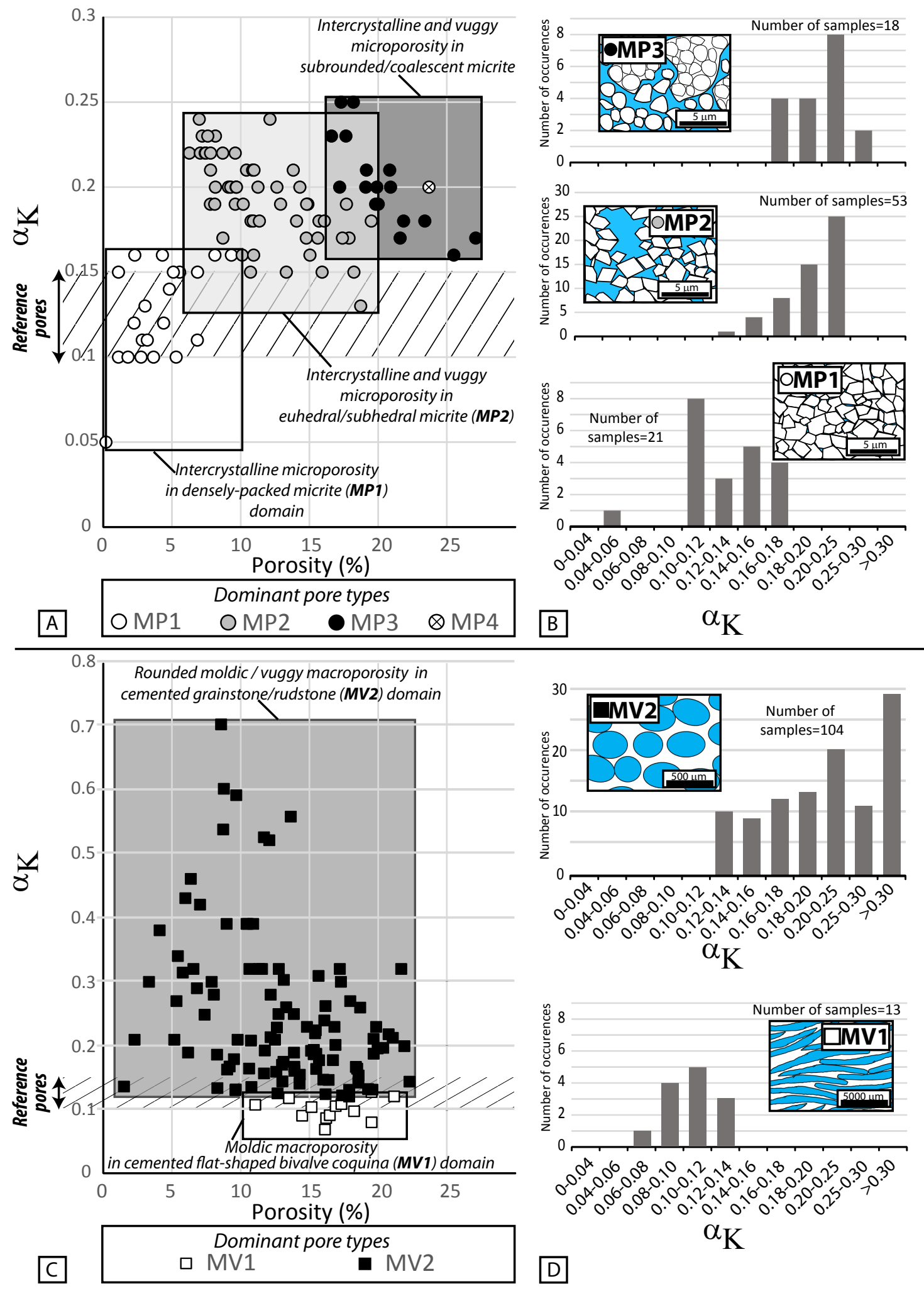

$D$ 
Figure 18
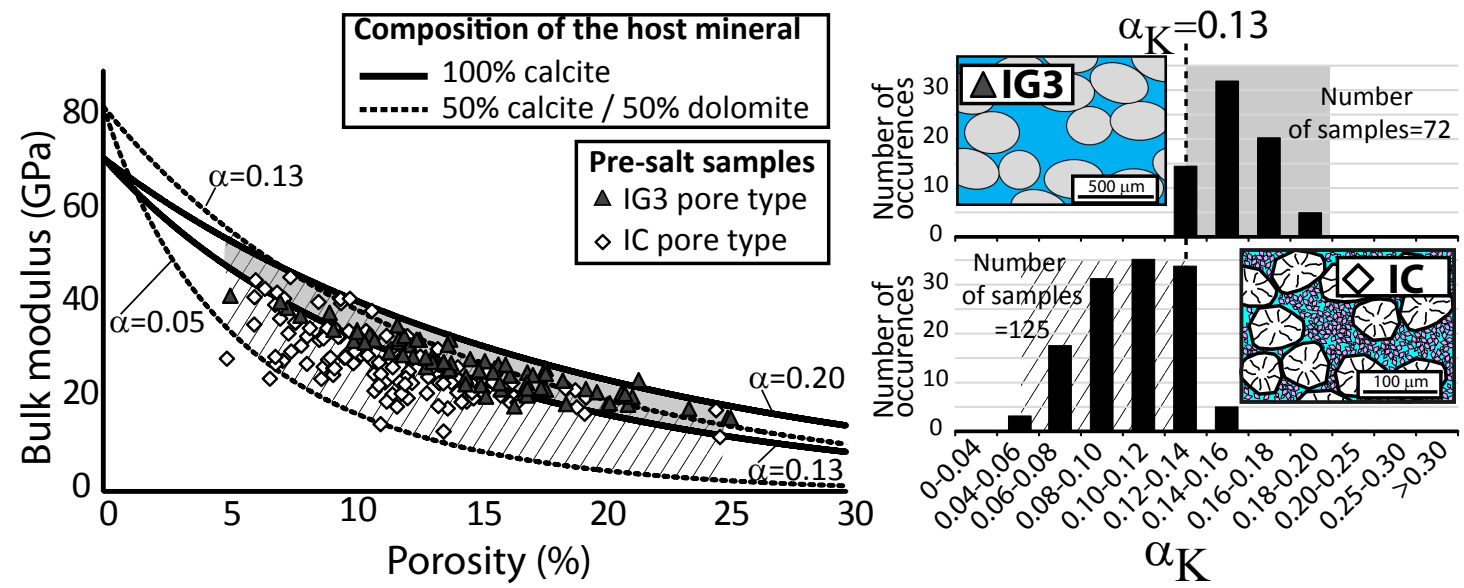
Figure 19
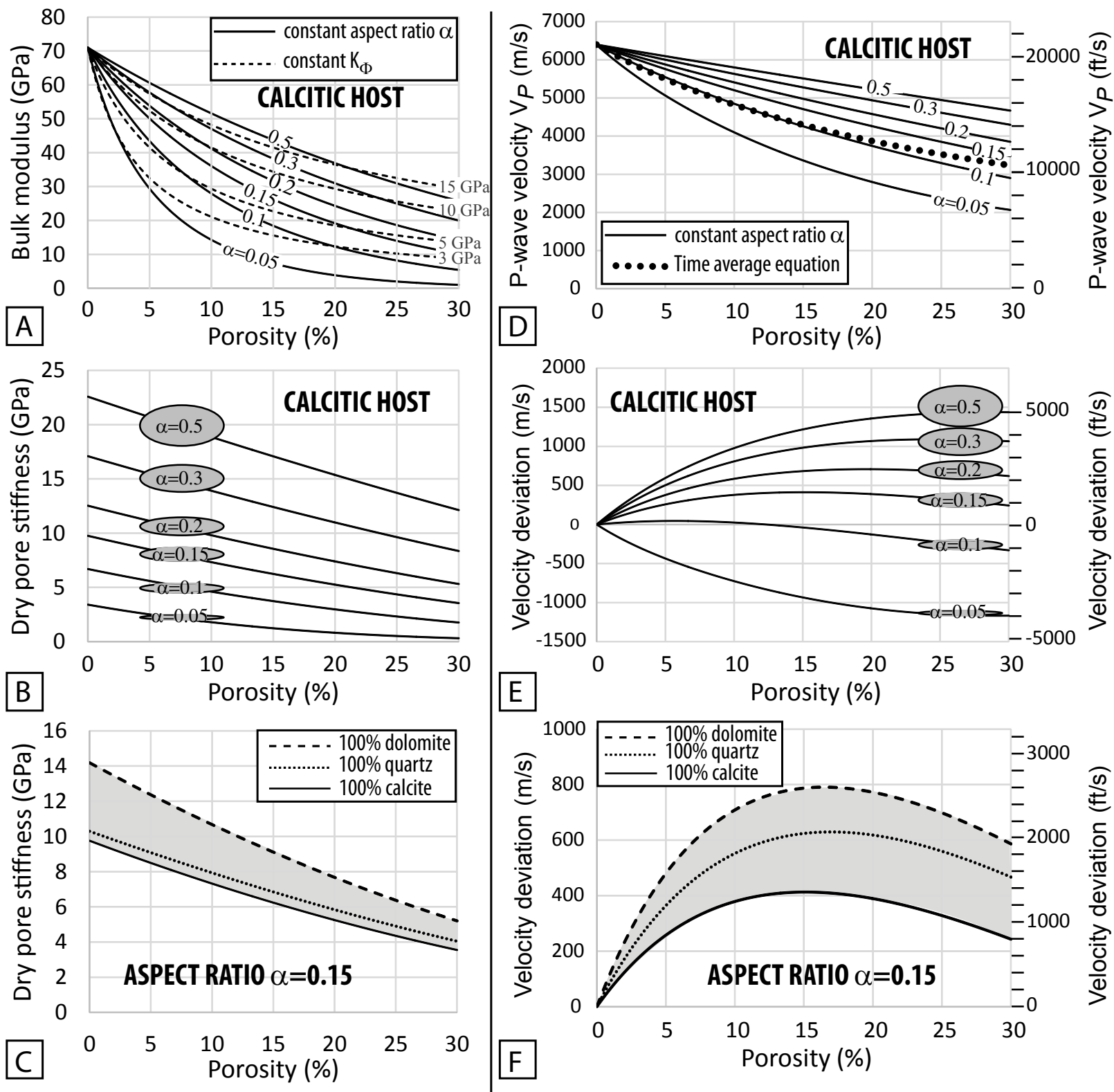
Figure 20

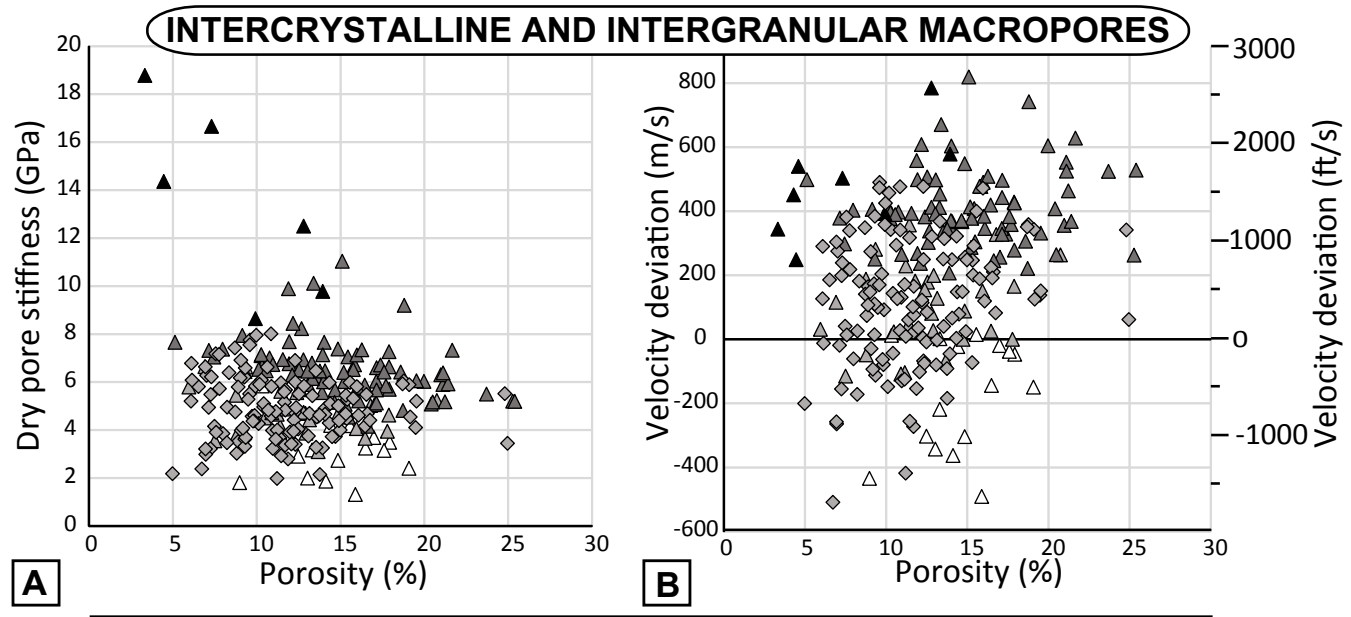

A

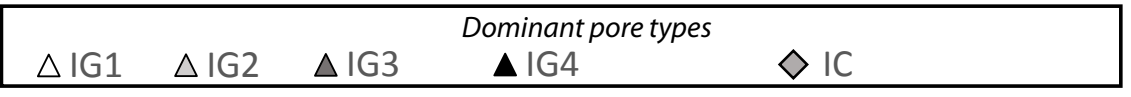

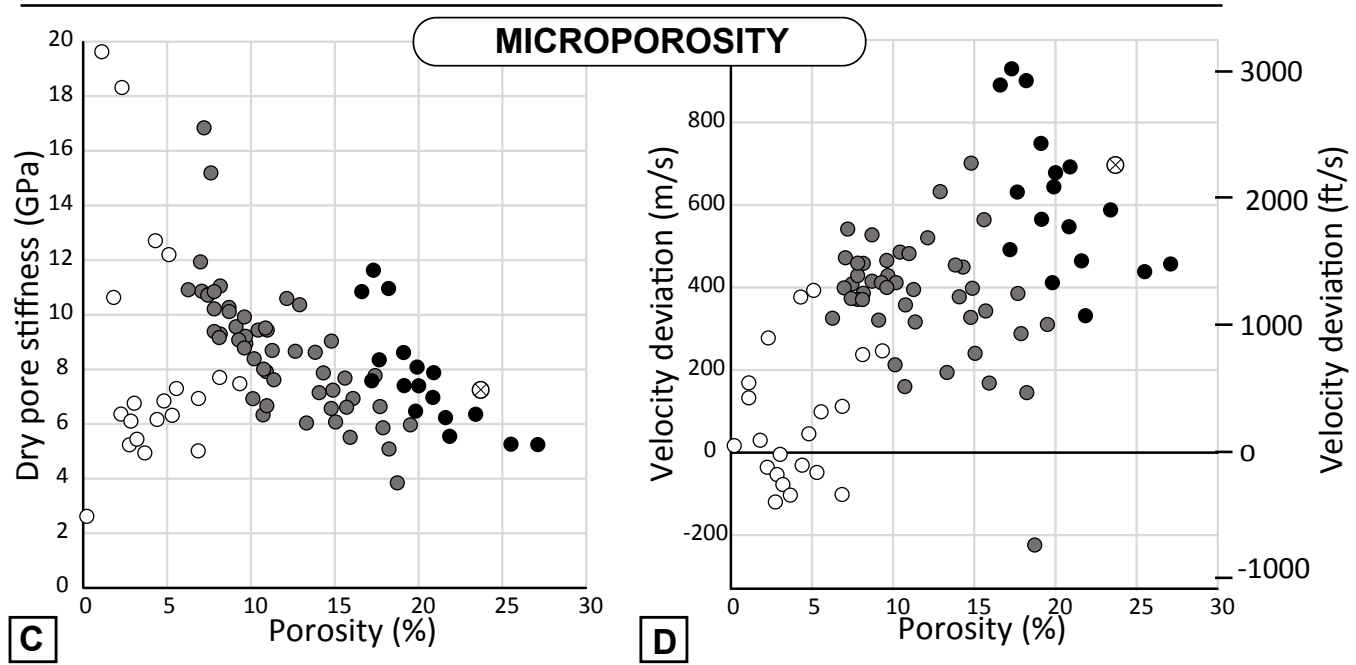

C

OMP1 OMP2

- MP3

$\otimes$ MP4

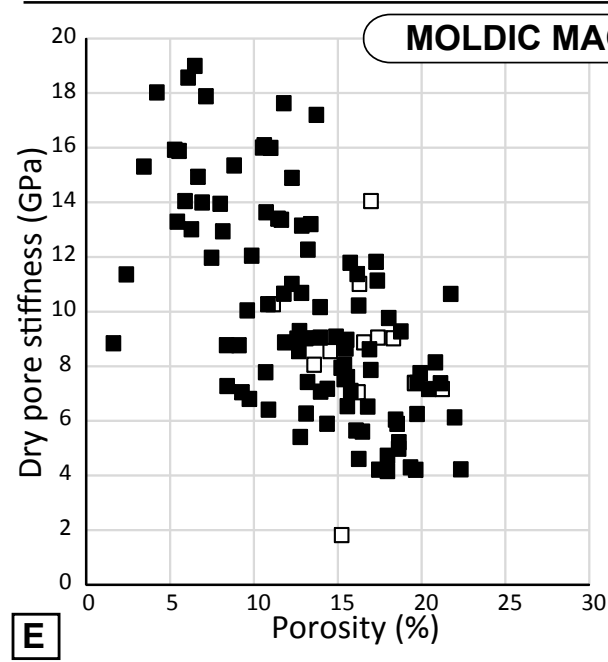

ROPOROSITY

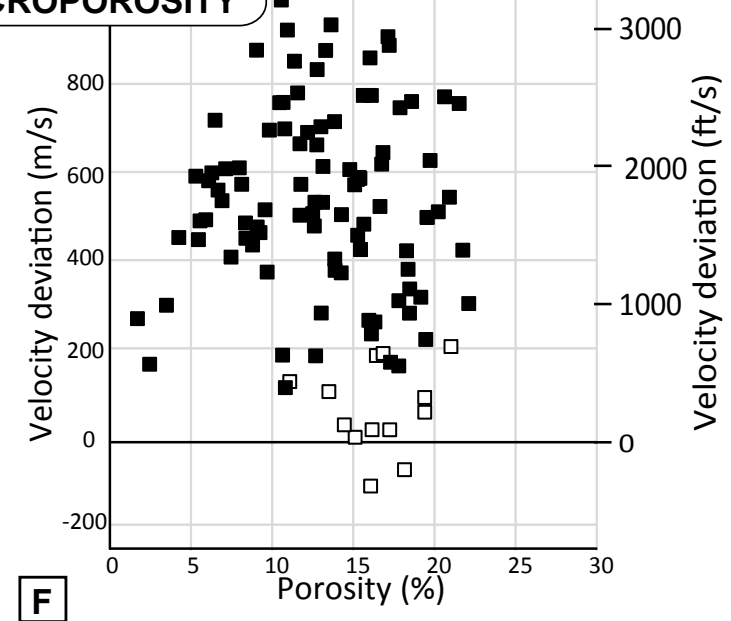


Figure 21

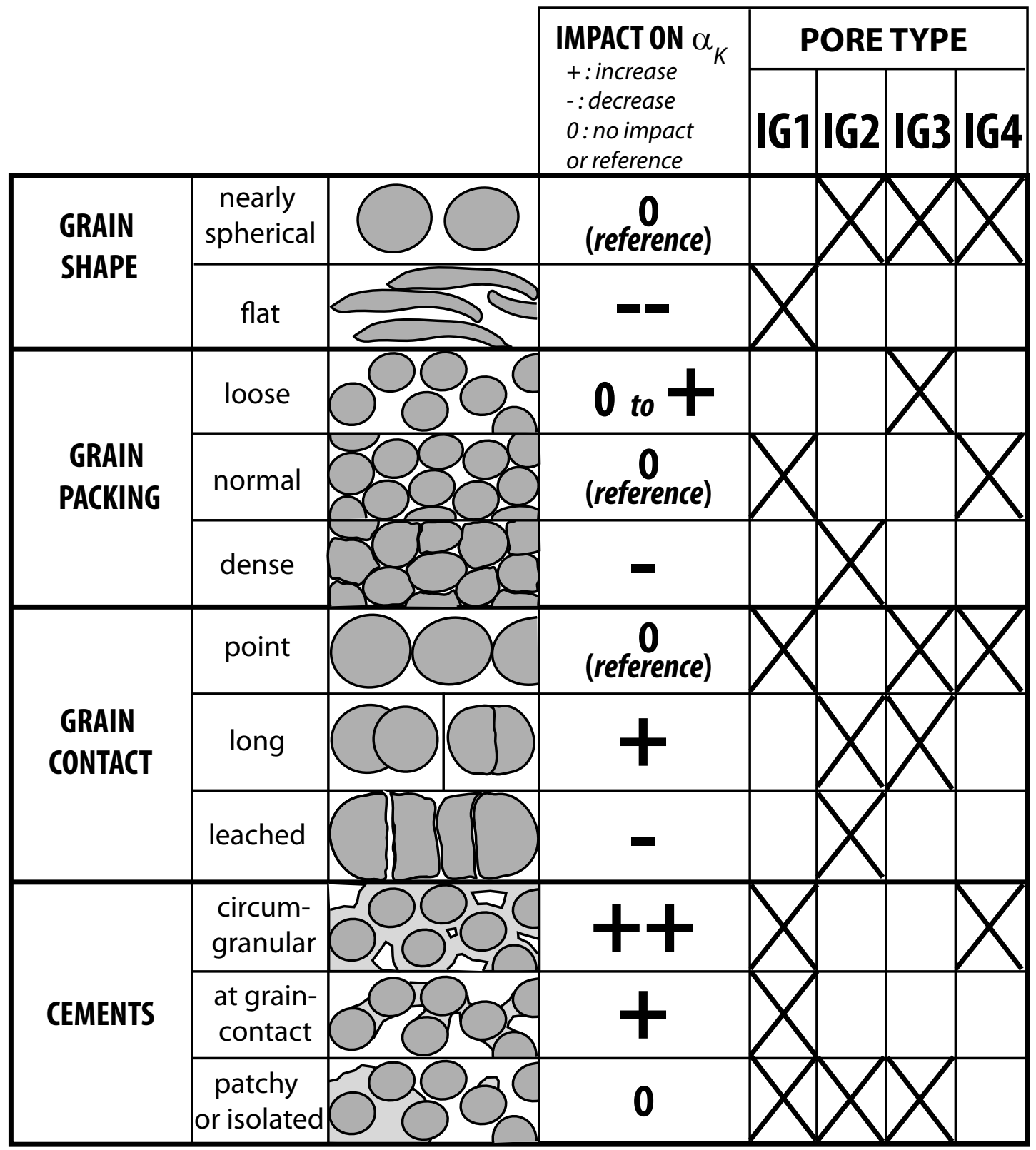




\begin{tabular}{cccc} 
& $\begin{array}{c}\text { Number } \\
\text { of studied } \\
\text { thin- } \\
\text { sections }\end{array}$ & $\begin{array}{c}\text { Velocity and } \\
\text { porosity } \\
\text { measurements }\end{array}$ & Reference \\
\hline $\begin{array}{c}\text { Lower Cretaceous Pre-salt coquina facies, } \\
\text { Brazil }\end{array}$ & 60 & well-logs & this paper \\
\hline $\begin{array}{c}\text { Lower Cretaceous Pre-salt spherulitic } \\
\text { facies, Brazil }\end{array}$ & 261 & well-logs & this paper \\
\hline $\begin{array}{c}\text { Lower Cretaceous (Urgonian) Limestone, } \\
\text { SE France }\end{array}$ & 107 & $\begin{array}{c}\text { laboratory } \\
\text { measurements }\end{array}$ & $\begin{array}{c}\text { Fournier } \text { et al., } \\
\text { 2014 }\end{array}$ \\
\hline $\begin{array}{c}\text { Upper Cretaceous redeposited carbonates, } \\
\text { Italy }\end{array}$ & 40 & $\begin{array}{c}\text { laboratory } \\
\text { measurements }\end{array}$ & $\begin{array}{c}\text { Hairabian } \text { et al., } \\
\text { 2014 }\end{array}$ \\
\hline
\end{tabular}

Table 1: Summary of the database used in the present work 


\begin{tabular}{|c|c|c|c|}
\hline & $\begin{array}{c}\text { Bulk } \\
\text { modulus } \\
(\mathrm{GPa})\end{array}$ & $\begin{array}{c}\text { Shear } \\
\text { modulus } \\
(\mathrm{GPa})\end{array}$ & $\begin{array}{l}\text { Density } \\
\left(\mathrm{g} . \mathrm{cm}^{-3}\right)\end{array}$ \\
\hline Calcite & 71 & 30 & 2.71 \\
\hline Silica (Quartz) & 38 & 45 & 2.65 \\
\hline Dolomite & 95 & 45 & 2.87 \\
\hline Water & 1.7 & & 1 \\
\hline Oil & 0.5 & & 0.8 \\
\hline
\end{tabular}

Table 2: Physical parameters of minerals and fluids 